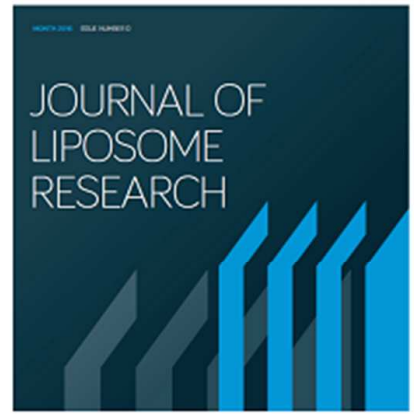

\title{
Intracellular uptake of EGCG-loaded deformable controlled release liposomes for skin cancer
}

\begin{tabular}{|r|l|}
\hline Journal: & Journal of Liposome Research \\
\hline Manuscript ID & Draft \\
\hline Danuscript Type: & Original Paper \\
\hline Complete List of Authors: & $\begin{array}{l}\text { Marwah, Mandeep; Aston University, Pharmacy } \\
\text { Perrie, Yvonne; University of Strathclyde, Pharmacy and Biomedical } \\
\text { Sciences } \\
\text { Badhan, Raj; Aston University, Pharmacy } \\
\text { Lowry, Deborah; University of Ulster, Pharmacy }\end{array}$ \\
\hline Keywords: & $\begin{array}{l}\text { Skin cancer, deformable liposomes, dermal release, controlled release, } \\
\text { elastic liposomes }\end{array}$ \\
\hline
\end{tabular}

\section{SCHOLARONE ${ }^{\text {M }}$}

Manuscripts 
(A)

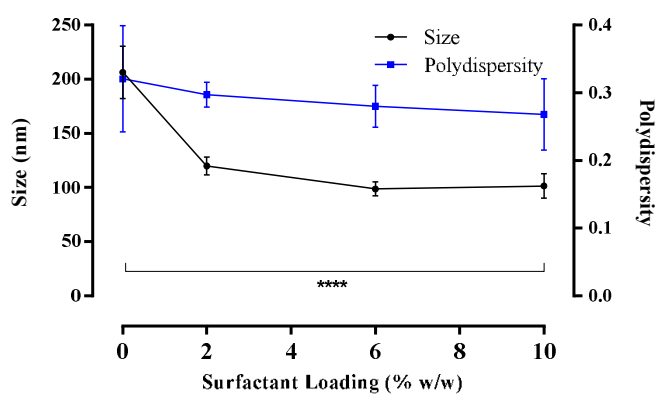

(B)

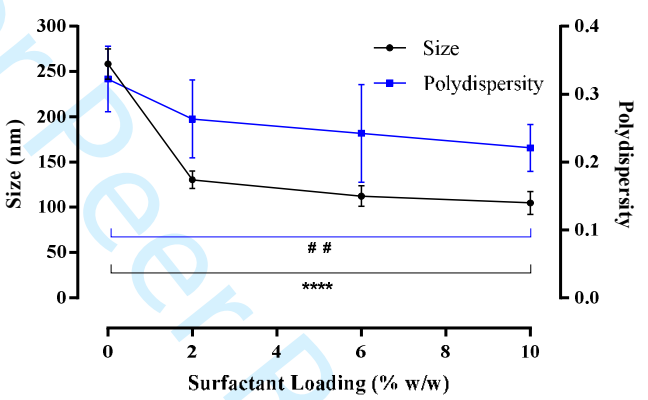

Fig. 1 Liposome size distribution and polydispersity of 'empty' and EGCG loaded liposomes

Liposome size distribution and polydispersity, determined by DLS, comparing (A) 'empty' and (B) EGCG loaded formulations with Tween $20(0-10 \% \mathrm{w} / \mathrm{w})$. Liposomes were prepared by the dry film hydration method and EGCG added during the lipid mixing stage. Data represents mean \pm SD. $\mathrm{n}=3$ independent batches. **** indicates statistical comparison between the size of liposome formulations with a $\mathrm{P} \leq 0.0001$. \# \# indicates statistical comparison between the polydispersity of liposome formulations with a $\mathrm{P} \leq 0.01$. 


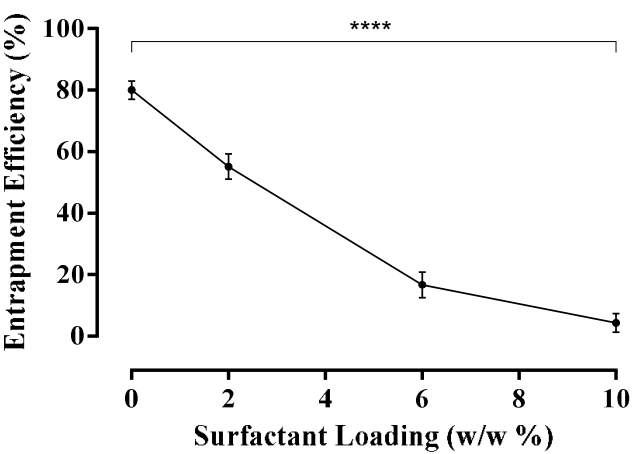

Fig. 2 Entrapment efficiency of EGCG in liposomes formulated with $0-10 \% \mathrm{w} / \mathrm{w}$ Tween 20

Entrapment efficiency (\%) of EGCG in liposomes formulated with varying amounts of Tween $20(0-10 \% \mathrm{w} / \mathrm{w})$ Data represents mean $\pm \mathrm{SD} . \mathrm{n}=3$ independent batches. $* * * *$ indicates statistical comparison between the entrapment efficiency of liposome formulations with a $\mathrm{P} \leq 0.0001$. 


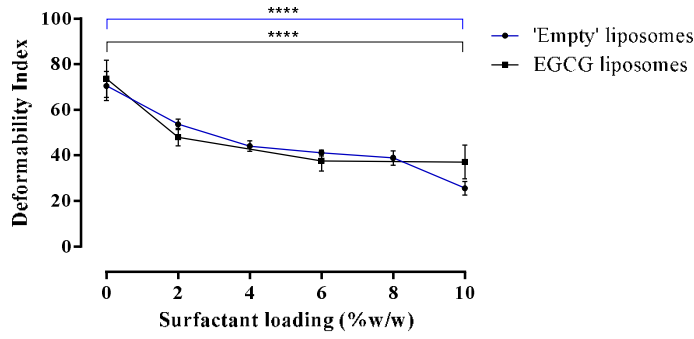

Fig. 3 Deformability index for 'empty' and EGCG loaded liposomes

Deformability index following extrusion through $50 \mathrm{~nm}$ membranes for 'empty' and EGCG loaded liposomes with increasing surfactant loading up to a maximum of $10 \% \mathrm{w} / \mathrm{w}$. Liposomes were prepared adapting the dry film method adding the surfactant and adding EGCG during the lipid mixing stage. The preparation was vortexed and then extruded though the membranes. Data represents mean \pm SD. $\mathrm{n}=3$ independent batches. **** indicates statistical comparison between the DI of liposome formulations with a $\mathrm{P} \leq 0.0001$. 


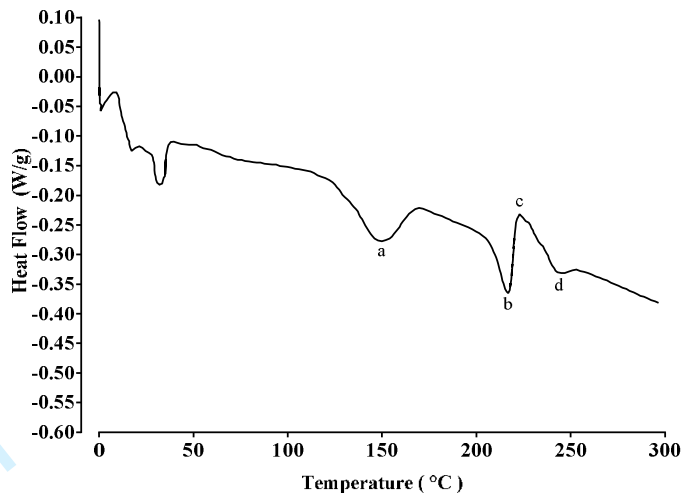

Fig. 4 Differential scanning calorimetry scan of EGCG

All experimental runs commenced at an initial temperature of $0{ }^{\circ} \mathrm{C}$ with a scan rate of $10{ }^{\circ} \mathrm{C} / \mathrm{min}$ to $300{ }^{\circ} \mathrm{C}$. Peak $\mathrm{a}$ and $\mathrm{b}$ are related to the epimer of EGCG, GCG. Peak c represents the glass transition temperature $\left(\mathrm{T}_{\mathrm{c}}\right)$ of EGCG was at $220{ }^{\circ} \mathrm{C}$ and the melting point $\left(\mathrm{T}_{\mathrm{m}}\right)$ of EGCG was at $245^{\circ} \mathrm{C}$. 
(A)

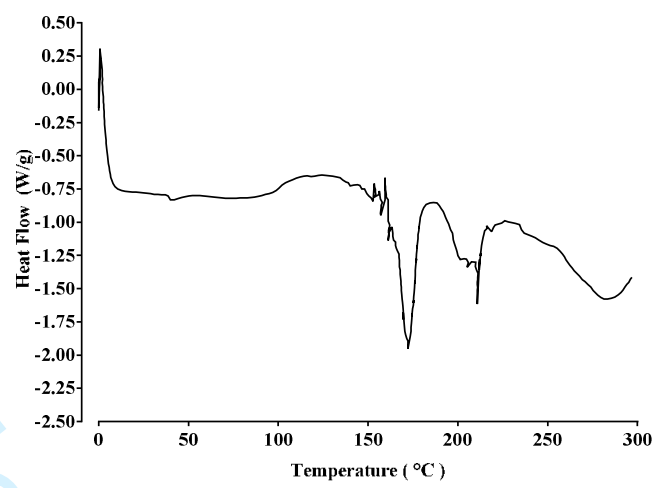

(B)

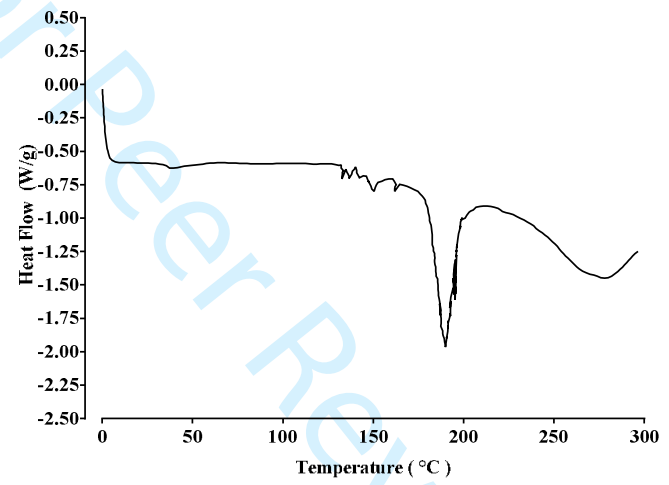

Fig. 5 Differential scanning calorimetry analysis scans of PC, cholesterol and Tween 20 and EGCG blends

DSC analysis scans of (A) PC, cholesterol and Tween 20 blend and (B) PC, cholesterol, Tween 20 and EGCG blend. The $\mathrm{T}_{\mathrm{m}}$ of the lipid mixture is $172{ }^{\circ} \mathrm{C}$, and upon addition of EGCG, the $\mathrm{T}_{\mathrm{m}}$ was $191{ }^{\circ} \mathrm{C}$. All experimental runs started at an initial temperature of $0{ }^{\circ} \mathrm{C}$, purged under nitrogen gas, with a scan rate of $10^{\circ} \mathrm{C} / \mathrm{min}$ to $300^{\circ} \mathrm{C}$. 


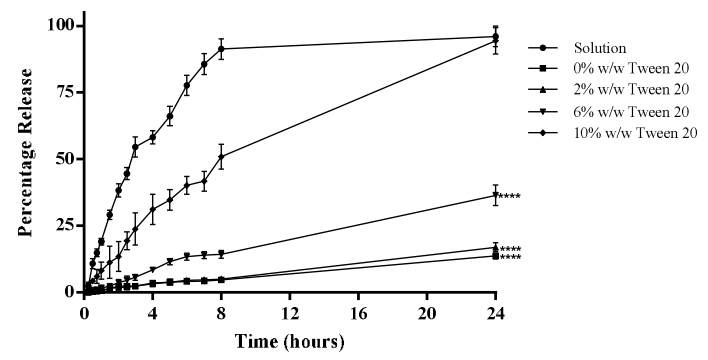

Fig. 6 In-vitro percentage EGCG cumulative release profiles from solution and liposomal formulations

EGCG release profiles from solution and liposomes formulated with $0,2,6$ or $10 \% \mathrm{w} / \mathrm{w}$ Tween 20 over 24 hours. Liposomes were prepared adapting the dry film method adding the surfactant and EGCG during the lipid mixing stage. A diffusion cell dialysis system was used to evaluate in-vitro drug release. Data represents mean \pm SD. $\mathrm{n}=3$ independent batches. **** indicates statistical comparison between the EGCG release of liposome formulations with a $\mathrm{P} \leq 0.0001$. 


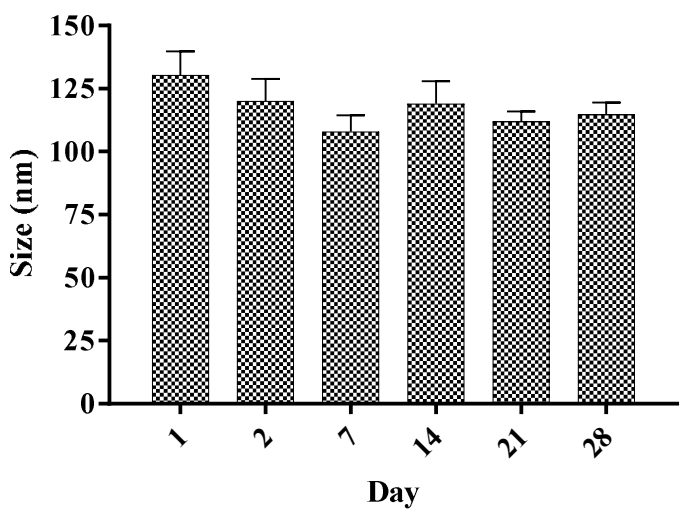

Fig. 7 Stability of EGCG loaded liposomes as determined by size

Size of EGCG loaded liposomes formulated with $0-10 \% \mathrm{w} / \mathrm{w}$ Tween 20 , using DLS, formulated with up to $10 \%$ w/w Tween 20 measured on various days $(1,7,14,21$ and 28). Data represents mean $\pm S D . n=6$ independent batches. 


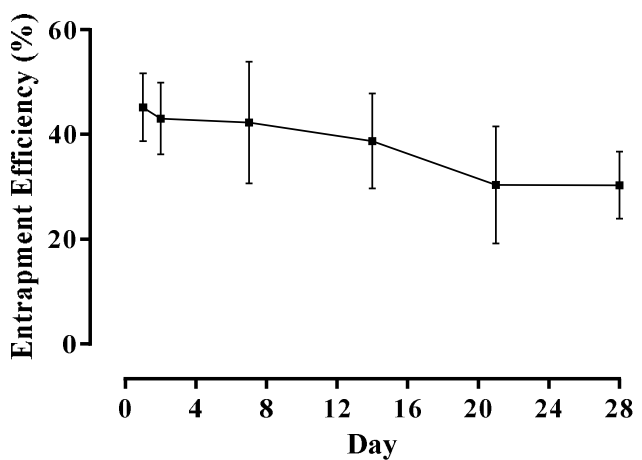

Fig. 8 Liposome encapsulation efficiency for EGCG

Liposome encapsulation efficiency for EGCG in liposomes formulated with $2 \% \mathrm{w} / \mathrm{w}$ Tween 20 liposomes over 28 days. Liposomes were prepared adapting the dry film method adding the surfactant and drug during the lipid mixing stage. The preparation was then washed via centrifugation. The quantity of EGCG in supernatant over 28 days was then analysed by HPLC coupled with UV detection to assess liposome stability. Data represents mean \pm SD. $n=6$ independent batches. 
(A)

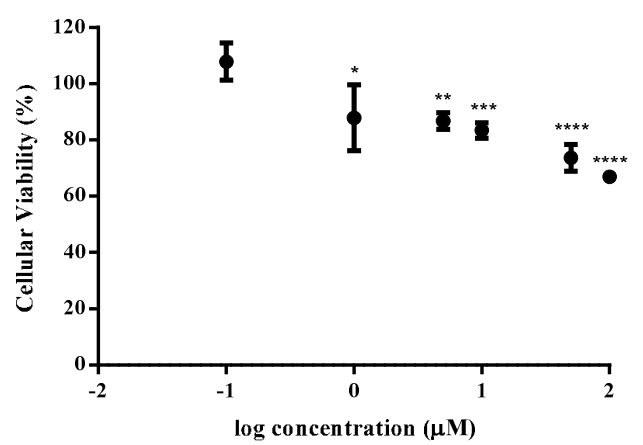

(B)

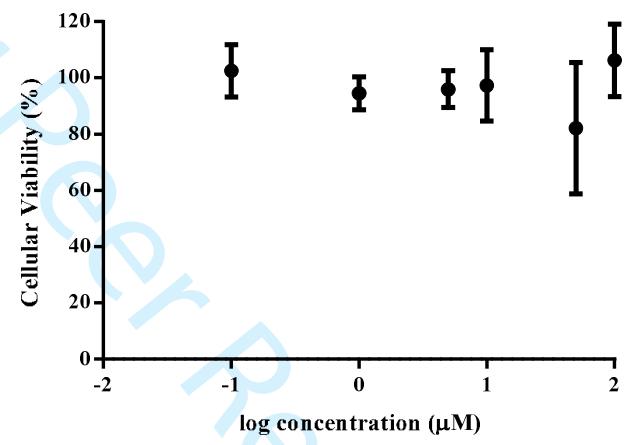

Fig. 9 Cellular toxicity of EGCG

HDFa (A) and HaCat (B) cells were grown on a 96-well plate at a density of $50 \times 10^{3}$ cells per well and exposed to various concentrations of EGCG $(0.01-100 \mu \mathrm{M})$ for 24 hours. Thereafter $25 \mu \mathrm{L}$ of a 12.5:1 parts mixture of XTT to menadione was added each well. Plates were incubated for 3 hours at $37^{\circ} \mathrm{C}$ and the absorbance read at $450 \mathrm{~nm}$. Data is reported as mean $\pm \mathrm{SD}$ with 6 replicates per compound in at 3 independent experiments. $* * * *$, $* * *, * *, *$ indicates statistical comparison between the entrapment efficiency of liposome formulations with a $\mathrm{P}$ $\leq 0.0001,0.001,0.01$ and 0.05 respectively. 


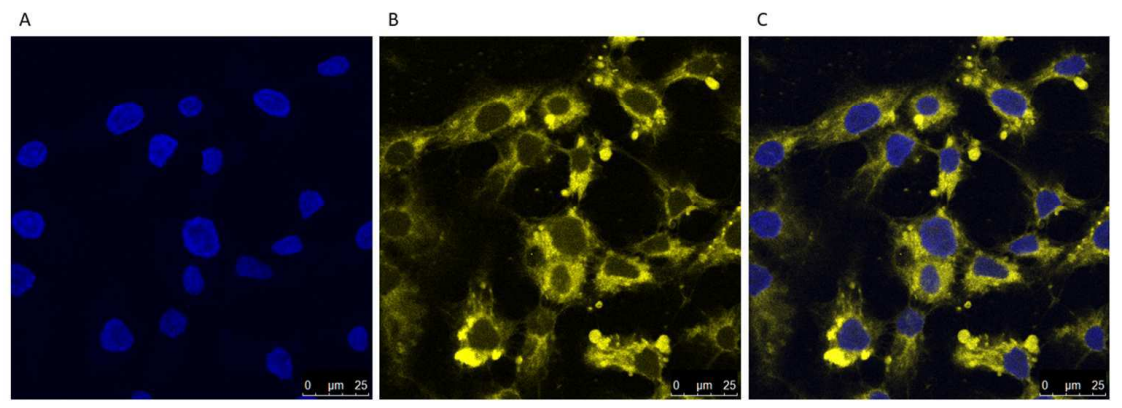

Fig. 10 Localisation of DilC labelled liposomes loaded with EGCG and 2\% w/w Tween 20 in HaCat cells

Cells were grown on the coverslips for 2 days. Cell nuclei were visualised using (A) DAPI (Blue). Liposomes were formulated with DilC for visualisation (B) (yellow). Liposome localisation within the cell is shown in the merged image $(C)$. 


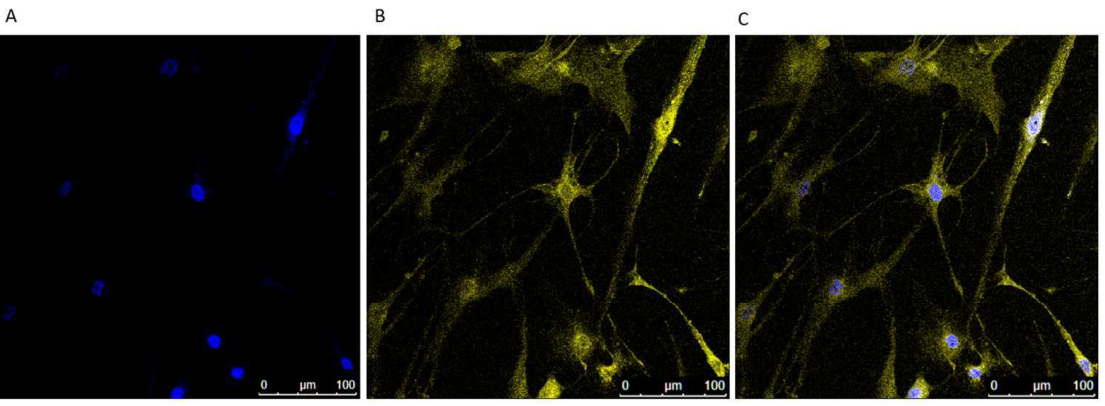

Fig. 11 Localisation of DilC labelled liposomes loaded with EGCG and 2\% w/w Tween 20 in HDFa cells

Cells were grown on the coverslips for 2 days. Cell nuclei were visualised using (A) DAPI (Blue). Liposomes were formulated with DilC for visualisation (B) (yellow). Liposome localisation within the cell is shown in the merged image $(\mathrm{C})$. 


\section{Intracellular uptake of EGCG-loaded deformable controlled release liposomes for skin} 2 cancer

3

4 


\section{ABSTRACT}

6 Caucasian population groups have a higher propensity to develop skin cancer, and associated

7 clinical interventions often present substantial financial burden on healthcare services.

8 Conventional treatments are often not suitable for all patient groups as a result of poor

9 efficacy and toxicity profiles. The primary objective of this study was to develop a

10 deformable liposomal formulation, the properties of which being dictated by the surfactant

11 Tween 20, for the dermal cellular delivery of epigallocatechin gallatein (EGCG), a compound

12 possessing antineoplastic properties. Results demonstrated a significant decrease in liposome

13 deformability index $(73.66 \pm 8.14$ to $37.06 \pm 7.41)$ as Tween 20 loading increased from 0 to

$1410 \% \mathrm{w} / \mathrm{w}$, indicating an increase in elasticity. EGCG release over 24-hours demonstrated

15 Tween 20 directly incorporation increased release from $13.7 \% \pm 1.1 \%$ to $94.4 \% \pm 4.9 \%$

16 (for 0 and $10 \%$ w/w Tween 20 respectively). Finally, we demonstrated DilC-loaded

17 deformable liposomes were localised intracellularly within human dermal fibroblast and

18 keratinocyte cells within 2-hours. Thus it was evident deformable liposomes are useful in

19 enhancing drug penetration into dermal cells and would be useful in developing a controlled-

20 release formulation.

21 KEYWORDS: Skin cancer; deformable liposomes; dermal release; controlled release;

22 elastic liposomes 


\section{Introduction}

Skin cancer is emerging as an increasing public health problem particularly in developed countries [1]. Currently, 2-3 million non-melanoma skin cancers and 132,000 melanoma skin cancers occur globally each year [2]. The large number of cases diagnosed present as a substantial burden to healthcare services [3, 4, 2]. Despite the fact that the majority of skin cancers are treatable, malignant forms of the cancer results in over 9,000 deaths annually worldwide [5]. Current treatment approaches are limited to local surgery to remove the tumour in addition to topical treatments with cream formulations. However, surgical removal may not be suitable for all patients whilst topical therapies are often linked with poor patient compliance stemming from high dose frequency requirements and unpleasant side effects [6]. In addition, topical treatments may cause skin irritation, weeping, cracking and blistering causing discomfort and pain [7-9].

Strategies for cancer management are focused on chemoprevention and chemoprotection. Existing anticancer agents often demonstrate poor safety profiles in addition to unpleasant side effect profiles, and there is an urgent need for novel agents which are both efficacious and possess a limited toxicity profile to non-malignant dermal tissue [1012]. One group of compounds that have gained interest recently as novel candidates for this purpose are flavonoids, naturally occurring chemicals abundantly expressed in food and drink, and in particular the green tea catechin, epigallocatechin gallatein (EGCG) which is increasingly being exploited for its chemoprevention properties [13-15]. EGCG has been found to affect specific biological processes that could be exploited as targets for the prevention and treatment of cancer [16], and has been demonstrated to possess properties associated with the induction of apoptosis [17], promotion of cell growth arrest by altering the expression of cell cycle regulatory proteins [17], activation of killer caspases and the 
suppression of oncogenic transcription factors $[18,19,15]$ and pluripotency maintaining factors [20]. However, the application of naturally occurring compounds as chemopreventative and chemoprotective strategies for skin cancer management has so far been received with limited success and this may be largely due to inefficient delivery systems and limited oral bioavailability of promising agents [21-23]. Consequently, to achieve maximum clinical efficacy, novel approaches are required to enhance compound bioavailability, of which dermal delivery is particularly promising.

The principle function of mammalian skin is to offer protection from environmental chemicals and xenobiotics [24]. The penetration of drugs across the skin is significantly inhibited by the skin's inherent barrier properties [25] thus there is a need to develop carrier systems to enhance penetrability. To fulfil this goal, when applied topically nanoparticle mediated delivery systems (e.g. microemulsions, liposomes, ethosomes, deformable liposomes and solid lipid nanoparticles), would benefit the direct dermal delivery of compounds across the stratum corneum [26-28]. Additionally, such nano-scale structures are capable of improving drug loading, enhancing systemic bioavailability, imparting a sustained release profile and allowing targeted drug delivery [29, 30]. Furthermore, the topical application of such carriers reduces the incidence of undesirable side effects arising from systemic administration and enhances systemic absorption of drugs after topical application with permeation enhancers which irreversibly disrupt the stratum corneum $[29,30]$. Controversy however surrounds the use of conventional liposomes due to their large size preventing skin penetration $[31,28,32,33]$, Gregor Cevc [34] demonstrated that modification of the chemical composition of the lipid bilayer so as to decease its Young's modulus resulted in the formation of deformable liposomes. These are able to gain access to the viable epidermis by overcoming the physical constraints imposed by the stratum corneum by diminishing the membrane elastic energy required for the liposome to deform and fit 
77 through an aperture size smaller than their original diameter following which reforming to

78 their original shape $[35,36,31]$. By being able to change shape and volume at minimal

79 energetic cost, these structures may penetrate across hydrophilic pathways of intact skin [37,

80 36]. Deformable liposomes often include additional components designed to make the

81 membrane more liable to deformation and these are termed edge-activators, typically

82 including surfactants such as Tweens, bile salts and Myrj [38]. The inclusion of this extra

83 component destabilises the vesicle bilayers by reducing the amount of energy required to

84 expand the interface allowing the liposome to become more elastic thus increasing the flux

85 across the skin [38-40].

The primary aim of this study was to develop and characterise a deformable

87 controlled release liposome formulation for targeting toward intracellular uptake into dermal cells. The objectives of the study were therefore to: (i) assess the impact of the edge-activator Tween 20 on liposomal formulation size; (ii) characterise resultant liposomes vesicle size, surface charge and encapsulation efficiency; (iii) quantify deformability of resultant liposomes using a deformability index (DI); (iv) assess release of EGCG; (v) assess the deformable liposome stability. ; (vi) assess cellular toxicity of EGCG and (vii) assess intracellular uptake in human dermal fibroblast and keratinocyte cells.

\section{Materials and methods}

\subsection{Materials}

Phosphatidylcholine (PC) was obtained from Avanti Polar Lipids. Cholesterol, Tween 20 and EGCG were obtained from Sigma-Aldrich. All other reagents including methanol and chloroform were obtained from Fisher Scientific. Ultrapure water was obtained from a Milli- 
100

101

102

103

104

105

106

107

108

109

110

111

112

113

114

115

116

117

118

119

Q purification system (Millipore, Billerica, MA, US). Human dermal fibroblasts (HDFa) isolated from adult skin and all cell culture reagents (Medium 106 and low serum growth supplement (LSGS) kit containing supplemented medium containing foetal bovine serum, 2 $\% \mathrm{v} / \mathrm{v}$, hydrocortisone $1 \mu \mathrm{g} / \mathrm{mL}$, human epidermal growth factor, $10 \mathrm{ng} / \mathrm{mL}$, basic fibroblast growth factor, $3 \mathrm{ng} / \mathrm{mL}$, heparin, $10 \mu \mathrm{g} / \mathrm{mL}$; DMEM media supplemented with $1 \% \mathrm{~L}$ glutamine, $10 \%$ FBS, $1 \%$ Penicillin Streptomycin and $0.25 \%$ amphotericin) were obtained from Life technologies (Carlsbad, California, US). Immortalized human keratinocytes (HaCat) cells were a kind gift from Dr Andrew Sanders (Cardiff China Medical Research Collaborative, Cardiff University, Henry Wellcome Building, Heath Park, Cardiff, CF14 $4 \mathrm{XN})$.

\subsection{Methods}

\subsubsection{Preparation of deformable liposomes with or without an edge activator}

Liposomes were prepared by adapting the film hydration method established by Bangham et al., (1965) [41]. PC and cholesterol (16:8 $\mu \mathrm{M})$ were dispersed in an organic solvent mixture consisting of chloroform and methanol in a 9:1 ratio in a round bottomed flask $[40,38,26,42,41]$. Subsequently, the organic solvent was removed by rotary evaporation for 5 minutes at $35^{\circ} \mathrm{C}$, followed by purging with nitrogen gas. The resultant dry film residue was hydrated by the addition of $4 \mathrm{~mL}$ water containing edge activator (up to $10 \%$ $\mathrm{w} / \mathrm{w}$ of the formulation) and $1 \mathrm{mg}$ of EGCG at a temperature above the transition temperature of the phospholipid (between -7 to $-15^{\circ} \mathrm{C}$ ) [43] and vortexed for 5 minutes to form multilamellar vesicles (MLV). The resulting particles were extruded 21 times through 100$\mathrm{nm}$ diameter polycarbonate membranes, using an Avanti Mini Extruder to produce unilamellar vesicles. The formed liposomes were equilibrated for $30 \mathrm{~min}$ above their transition temperatures $\left(-15^{\circ} \mathrm{C}\right)$ before being subjected to further characterisation $[44,45,43]$. 
The mean particle size and the polydispersity index (measurement of the level of

127 homogeneity of particle sizes) of liposomes were measured by dynamic light scattering

128 (DLS) using a Zetaplus (Brookhaven Instruments) following dilution with distilled water (1:4

129 ratio) to ensure intensity adjustment. A polydispersity value of $<0.2$ indicates a homogenous

130 vesicle population, while polydispersity of $>0.3$ indicates heterogeneity [46]. The particle

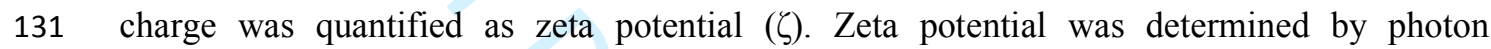

132 correlation spectroscopy using a Zetaplus (Brookhaven Instruments). The samples were

133 diluted three-fold and assessed in triplicate.

134 2.2.3 HPLC-UV detection of EGCG

135 Detection of EGCG was assessed using reverse phase HPLC methodology. A Waters

136 Alliance separation module HPLC with UV detection was utilised at an operating wavelength 137 of $275 \mathrm{~nm}$ [47] with a Waters X select column (5 $\mu \mathrm{m} \mathrm{C18} 4.6 \times 150 \mathrm{~mm})$, with a $10 \mu \mathrm{L}$ 138 injection volume. The mobile phase comprised of a $70: 30$ ratio of $0.1 \%$ TFA in water to 139 methanol at a flow rate of $1 \mathrm{~mL} / \mathrm{min}$. Stock solutions and standard solutions of EGCG were 140 prepared with both water and ethanol ranging from $0.5-500 \mu \mathrm{g} / \mathrm{mL}$. A final A calibration 141 curve with an $\mathrm{R}^{2}$ of 0.997 and linear equation of $\mathrm{y}=1 \mathrm{x} 10^{7} \cdot \mathrm{x}$ was obtained.

\subsubsection{Entrapment efficiency of EGCG}

The entrapment efficiency of EGCG loaded deformable liposomes was determined by centrifuging samples and quantifying the EGCG in the supernatant. Samples were centrifuged at $18,000 \mathrm{rpm}$ for $30 \mathrm{~min}$ at $4^{\circ} \mathrm{C}$ in an Optima ${ }^{\mathrm{tm}} \mathrm{MAX}-\mathrm{XP}$ ultracentrifuge to separate the 
146 incorporated drug from the free drug. The supernatant was then analysed using HPLC to

147 determine the encapsulation efficiency of EGCG in liposomal formulations (Equation 1):

$$
E=\frac{D_{t}-D_{s}}{D_{t}} \times 100 \%
$$

149 where $E$ is the encapsulation efficiency $(\%), D_{t}$ is the total drug content $(\mathrm{mg})$ and $D_{s}$ is drug 150 content in supernatant (mg)

\section{$151 \quad$ 2.2.5 Assessment of liposomal deformability}

To assess the deformability of formulated liposomes, a liposome suspension $(6 \mathrm{~mL})$

153 consisting of a 16:8 micromolar ratio of PC to cholesterol formulated with up to $10 \% \mathrm{w} / \mathrm{w}$ of

154 Tween 20 solution (diluted 3 fold), was passed through a polycarbonate filter of $50 \mathrm{~nm}$ pore

155 size using a syringe driver (Cole Parmer, UK) set at $0.6 \mathrm{~mL} / \mathrm{min}$ for $10 \mathrm{~min}$. The mean

156 particle size and the polydispersity index of liposomes were subsequently quantified by DLS,

157 before and after filtration, to assess the ability of formulated liposomes to regain their size

158 after having been forced through a pore size smaller than their original diameter. The

159 deformability was quantified through the calculation of a deformability index (equation 2)

$160 \quad[32]:$

161

$$
D=100-\frac{L_{e}}{L} \times 100
$$

162 where $D$ is deformability, $L_{e}$ is size of extruded liposomes (nm), $L$ is size of liposomes (nm)

163 prior to extrusion.

\subsubsection{Differential scanning calorimetry of EGCG and EGCG lipid blends}

165 To assess thermal characteristics of materials including melting temperatures, phase

166 transitions and heat capacity changes of liposomes, EGCG and ratios of lipid, surfactant and 
167 drug mixtures corresponding to that of the liposome formulation, were analysed in the solid

168 state using a TA Instruments Q200 Thermal Analysis Differential scanning calorimetry

169 (DSC). $3 \mathrm{mg}$ of EGCG was weighed into T-Zero aluminium pans and then hermetically

170 sealed. All experimental runs commenced at an initial temperature of $0^{\circ} \mathrm{C}$, purged under

171 nitrogen gas, with a scan rate of $10^{\circ} \mathrm{C} / \mathrm{min}$ to $300^{\circ} \mathrm{C}$.

$172 \quad$ 2.2.7 In-vitro EGCG release studies

173 To assess the impact of inclusion of Tween 20 on EGCG from liposomal formulations, a

174 side — by-side diffusion cell (PermeGear diffusion cell, Hellertown, USA) was maintained at

$17535{ }^{\circ} \mathrm{C}$. Release was assessed over a 24 hour period from an EGCG aqueous solution (0.1

$176 \mathrm{mg} / \mathrm{mL}$ ) and EGCG-loaded liposomes (final loading for liposomes formulated with 0, 2, 6

177 and $10 \% \mathrm{w} / \mathrm{w}$ Tween 20 was $0.80,0.55,0.17$ and $0.04 \mathrm{mg} / \mathrm{mL}$ respectively). $10 \mathrm{~mL}$ of each

178 formulation was placed into the donor side of the diffusion cell and release across a $50 \mathrm{~nm}$

179 membrane (Whatman ${ }^{\circledR}$ ) into the receiver side containing $100 \mathrm{~mL}$ of dermal dissolution

180 media with a stirrer was measured. The release media was sampled with volume replacement

181 (0.5 mL) over 24 hours and analysed using HPLC-UV quantification.

$182 \quad$ 2.2.8 In-vitro drug release kinetics

183 Several kinetic drug release mathematical models were used to assess drug release from the

184 formulations. The best-fit to the mathematical models described below confirmed the

185 appropriate release kinetics:

186 Zero order model: $\frac{M_{t}}{M_{\infty}}=k_{0} \cdot \mathrm{t}$

187 where $M_{\mathrm{t}} / M_{\infty}$ is the drug fraction released at time $t$ and $k_{0}$ is the zero-order release constant.

188 First order model: $\frac{M_{t}}{M_{\infty}}=1-e^{-k_{1} t}$ 
189 where $M_{\mathrm{t}} / M_{\infty}$ is the drug fraction released at time $t$ and $k_{l}$ is the first-order release constant.

190 Higuchi model: $\frac{M_{t}}{M_{\infty}}=k_{H} \cdot t^{\frac{1}{2}}$

191 where $M_{\mathrm{t}} / M_{\infty}$ is the drug fraction released at time $t$ and $k_{H}$ is the Higuchi constant.

192 Korsmeyer-Peppas Model: $\frac{C_{t}}{C}=K t^{n}$

193 where $C_{t} / C$ is fraction of drug released at time $t, k$ is the release rate constant. The value of $n$ 194 is valuable in understanding drug release mechanisms. When $n \leq 0.45$ drug release is 195 diffusion controlled and can be referred to as 'Fickian' diffusion and when $n>0.89$ the 196 diffusion is indicative of erosion controlled drug release or class-II kinetics. For situations 197 where $0.45<n \leq 0.89$ the diffusion is a complex mixture of both processes and often termed 198 anomalous transport. In all cases this is based on the assumption of release from a cylinder 199 and applied to cumulative release rates $<60 \%[48]$

200 Mathematical models to assess release kinetics were fit using Microsoft Excel ${ }^{\circledR}$. Zero order, 201 first order, Higuchi and Korsmeyer-Peppas release profiles were applied to release from drug 202 solution and drug loaded liposome solution following which regression analysis techniques 203 were employed to determine the probable drug-release. The release kinetic model displaying 204 the highest $r^{2}$ metric $(\geq 0.95)$ was determined to be the mechanism, by which release occurred.

\subsubsection{Liposome stability}

206 The stability of liposomes was determined, as prepared in water, through the assessment of 207 particle size over a 28 -day period, stored in a stability cabinet maintained at $25 \pm 2{ }^{\circ} \mathrm{C}$ 208 (Firlabo, France) at a humidity of $60 \% \pm 5 \%$. Mean particle sizes were determined on days $2091,2,7,14,21$ and 28 by DLS. Furthermore, the encapsulation efficiency of drug loaded 210 liposomes was assessed over 4 weeks as detailed in section 2.2.4.

10 


\subsubsection{Development of an in-vitro cellular dermal model}

214

215

To develop an in-vitro system to assess cellular toxicity and cellular uptake of deformable liposomes into representative human dermal tissue, two dermal cell line were examined. Human dermal fibroblasts (HDFa) were cultured in Medium 106 supplemented with low serum growth supplement. Human epidermal keratinocytes (HaCaT) cells were revived and sustained in high glucose supplemented DMEM media. Media was replaced every 3 days. At $70-80 \%$ confluency, media was discarded and cells detached using Trypsin/EDTA incubated for $5 \mathrm{~min}$, prior to trypsin neutralisation with $3 \mathrm{~mL}$ growth media and subsequent centrifugation at $1200 \mathrm{rpm}$ for $10 \mathrm{~min}$ and resuspension in fresh media prior to being utilized for subsequent studies

\subsubsection{Cellular toxicity of liposomal formulations towards HDFa and HaCat cells}

To determine the cytotoxicity profile of EGCG towards HDFa and HaCat cells, a (2,3-Bis-(2-Methoxy-4-Nitro-5-Sulfophenyl)-2H-Tetrazolium-5-Carboxanilide (XTT) assay [49] was performed to measure cell viability after exposure to increasing concentrations of EGCG for 24 hours. Cells were seeded at a density of $50 \times 10^{3}$ cells per well into a 96-well plate and grown for 3 days. Thereafter, media was removed and cells were exposed to $100 \mu \mathrm{L}$ of 0.1-100 $\mu \mathrm{M}$ EGCG and incubated for 24 hours at $37^{\circ} \mathrm{C}$. Subsequently, $25 \mu \mathrm{L}$ of a 12.5:1 (XTT: menadione) was added each well and incubated for 3 hours at $37^{\circ} \mathrm{C}$ prior to the absorbance being read at $450 \mathrm{~nm}$. Assessment of EGCG toxicity to these cells was conducted through analysis of changes in XTT absorbance with increasing drug concentration.

\subsubsection{Intracellular uptake of deformable liposomes into HDFa and HaCat cells}


234 Liposomes, both deformable and non-deformable, were formulated with the addition of 0.25

$235 \mathrm{~mL}$ of a $0.1 \mathrm{mg} / \mathrm{mL}$ DilC during the lipid mixing stage. Unentrapped DilC was removed by 236 centrifuging liposomes at $18,000 \mathrm{~g}$ for $30 \mathrm{~min}$. Coverslips were coated for $30 \mathrm{~min}$ with poly237 -lysine $(0.01 \% \mathrm{w} / \mathrm{v})$ prior to the addition of cells at a density of $50 \times 10^{3}$ cells per coverslip. 238 After 24 hours, DilC loaded liposomes were diluted with 1 part of supplemented media (as 239 clarified in materials) and were then added to the coverslips and incubated for 2 hours at $24037^{\circ} \mathrm{C}$

241 Thereafter, coverslips were washed and fixed with $4 \% \mathrm{w} / \mathrm{v}$ paraformaldehyde for 5 minutes 242 at room temperature. Subsequently, coverslips were mounted onto glass slides with the 243 addition of a DAPI-containing mounting media. Cover slips were subsequently analysed in 244 an upright confocal microscope (Leica SP5 TCS II MP) and visualised with a 40× oil 245 immersion objective. Images were acquired using a helium-neon laser at $633 \mathrm{~nm}$ to visualise 246 DilC and a helium-neon laser to visualise DAPI at $461 \mathrm{~nm}$.

248 Unless otherwise stated, all results are presented as mean \pm standard deviation (SD).

249 Replicates of at least 3 were used for all studies. For multiwell plate assays replicates of 6 250 were used for each experimental condition with the study replicated 3 times. A one-way 251 ANOVA was used to determine any statistically significant difference between means tested. 252 A post-hoc Tukey's multiple comparisons test was then applied to assess differences between 253 groups. All the calculations were carried out using Graphpad 6 (GraphPad Inc., La Jolla, 254 CA).

\section{3. Results and discussion}


256 Emerging treatments for cancer management involve chemoprevention and chemoprotection.

257 Current anticancer agents tend to demonstrate a poor safety profile in addition to possess a 258 wide range of unpleasant side effects [10-12]. However, phytochemical flavonoids, such as 259 EGCG, are increasingly being investigated for their chemoprevention properties [13-15].

260 EGCG is a flavonoid found in green tea that possesses cytotoxic effects in cancerous skin 261 cells and thus may be a potentially viable candidate as a pharmacological anti-cancer agent 262 [16], given that it has been observed to induce apoptosis in cancer cells without affecting 263 normal cells [50, 17], in addition to the modulating expression of a number of genes involved 264 in cell proliferation, cell-cell contact and cell-matrix interactions [51].

265 However, the penetration of drugs across the skin is significantly hindered by the skin's 266 inherent barrier properties [25]. The use of deformable liposomes to aid dermal cellular 267 penetrability and uptake may be advantageous in the targeting of neoplastic agents to deeper 268 skin cellular layers when compared to conventional liposomes which may not be able to 269 penetrate through the narrow pore of the stratum corneum [39].

270 This focus of this study was to develop EGCG loaded slow release deformable liposomes.

271 EGCG liposomes were formulated with PC and cholesterol with the inclusion of Tween 20 as 272 a edge-activator with incorporation of up to $10 \% \mathrm{w} / \mathrm{w}$. Liposomal characteristics including 273 liposome size, charge, encapsulation efficiency, DI, release profile, stability, ceulluar toxicity 274 and uptake were was assessed.

\subsection{Liposome characterisation}

276 The impact of the inclusion of Tween 20 within the liposomal formulation on 277 liposome characteristics were observed. As the surfactant loading in the bilayer of 'empty' 278 liposomes increased, liposome diameter decreased from $206.45 \pm 24.33 \mathrm{~nm}$ for liposomes 
279 formulated with no surfactant to $101.61 \pm 11.27 \mathrm{~nm}$ for liposomes formulated with $10 \% \mathrm{w} / \mathrm{w}$

280 Tween 20 (Figure 1A). As the surfactant loading in the bilayer of EGCG loaded liposomes 281 increased, liposome diameter decreased, from $258.43 \pm 16.69 \mathrm{~nm}$ for liposomes formulated 282 with no surfactant compared with $104.95 \pm 12.56 \mathrm{~nm}$ for liposomes formulated with $10 \%$ $283 \mathrm{w} / \mathrm{w}$ Tween 20 (Figure 1B). The decrease in size was statistically significant for 'empty' and 284 EGCG loaded liposomes formulated with no surfactant compared with liposomes loaded with 2852,6 and $10 \% \mathrm{w} / \mathrm{w}$ Tween 20.

286 [Figure 1 near here]

287 The inclusion of surfactants into liposome formulations have previously been demonstrated 288 to decrease liposome size when compared to liposomes formulated in the absence of surfactant $[26,32]$. This may be as a result of a destabilising effect imparted by the surfactant on the bilayer [52], which results in a greater interaction of the phospholipid bilayer with the aqueous phase. A consequence of this would then be the overall formation of liposomes with a smaller diameter giving a greater surface area in contact with the aqueous phase. The inclusion of surfactant has been previously reported to decrease liposome size in comparison to conventional liposomes. A study formulating liposomes with Phospholipon® $90 \mathrm{G}$ and both Tween 80 and Span 80 reported a size reduction from $207 \mathrm{~nm}$ to $139 \mathrm{~nm}$ following inclusion of the surfactants [32].

A liposome preparation which is homogenous in size is important as final liposome size will partly determine the level of tissue distribution in-vivo in addition to influencing drug release kinetics. A polydispersity of up to 0.3 is considered homogenous [53, 32, 54]. As the loading of surfactant increased, the polydispersity of the liposomal formulation decreased, non-significantly from 0.33 to 0.27 and significantly $(\mathrm{P}<0$.) 0.32 to 0.22 for 'empty' 
liposomes (Figure 1a) and those loaded with EGCG respectively (Figure 1b). Therefore, the inclusion of Tween 20 within the liposome formulation appeared to improve homogeneity.

The magnitude of the zeta potential $(\zeta)$ indicates the degree of electrostatic repulsion between adjacent, similarly charged particles in a dispersion. Thus, it is a fundamental parameter thought to affect stability of liposomal formulations. All formulated liposomes demonstrated a near neutral charge (Table 1). A neutral liposomal surface charge is important to avoid skin irritation [55] however, this may subsequently lead to particle flocculation due to attractive forces between liposomes causing them to cluster [56].

\section{[Table 1 near here]}

In liposomes formulated with EGCG, as Tween 20 loading increased, a statistical significant decrease in EGCG entrapment was observed, $(\mathrm{P} \leq 0.0001)$, from $80.0 \pm 3.0 \%$ no surfactant to $4.3 \pm 3.0 \%$ with a $10 \% \mathrm{w} / \mathrm{w}$ loading of surfactant (Figure 2). This decrease in EGCG loading may be related to the difference in the molecular weight of EGCG and Tween 20. Tween 20, with larger molecular weight of $1227.54 \mathrm{~g} / \mathrm{mol}$ compared to that of EGCG ( $386.65 \mathrm{~g} / \mathrm{mol})$, may be assumed to be better poised to displace EGCG from the bilayer. Further, the hydrophobic tail of Tween 20 would have a high affinity to the chains in PC therefore displacing EGCG from the bilayer [57-59]. Furthermore, Tween 20 is known to enhance the solubility of drugs and therefore, as not all would be entrapped within the bilayer, this may allow increased EGCG solubilisation within the liposomal rehydration media [60]. It is also possible that the coexistence of vesicles and mixed micelles at high surfactant concentrations [61] may have reduced the compound entrapment in mixed micelles.

[Figure 2 near here] 
The degree of deformability of each formulation was determined by extrusion through

326 a polycarbonate filter with a pore size of $50 \mathrm{~nm}$. The mean particle size and the polydispersity

327 index of liposomes was quantified before and after filtration to assess liposome ability to regain size after having being forced through a pore size smaller than their original diameter.

329 The DI is defined as the degree the liposomes deformed; the greater the degree of 330 deformation the less elastic the liposomes are as they were unable to regain their previous 331 larger size. The DI following extrusion decreased with statistical significance $(\mathrm{P} \leq 0.0001)$ as 332 surfactant loading increased in 'empty' liposomes, from $70.8 \pm 6.5$ to $25.6 \pm 2.9 \%$ for 333 liposomes formulated with no surfactant compared with $25.6 \pm 2.93$ for liposomes formulated formulated with $10 \% \mathrm{w} / \mathrm{w}$ Tween 20 (Figure 3). These observations imply the liposomes were displaying elastic properties as they could deform in order to pass through an opening smaller than its own diameter whilst, to a certain degree regaining its size. Additionally, the presence of EGCG in the liposome formulation did not appear to affect the DI compared with liposomes formulated without. A study formulating liposomes with Phospholipon ${ }^{\circledR} 90 \mathrm{G}$ and both Tween 80 and Span 80 saw a size reduction observed surfactant to decrease the DI from $51.4 \pm 3.6$ to $17.3 \pm 5.2[32]$.

[Figure 3 near here]

Liposomes formulated with surfactant can deform as the surfactant has a propensity for highly curved structures (e.g. micelles and liposomes), thus diminishing the energy required for particle deformation. The surfactant is able to diminish the energy required for particle deformation and accommodate particle shape changes of the liposomes under stress 
349 [62]. These surfactants may have interacted with the PC with strong affinity but in reversible 350 mode. The reversible binding mode might have provided the deformability upon physical 351 stress [38].

For liposomes to deform, a source of energy is required [63-65]. In our systems, 'energy' was supplied to this system in the form of pressure as a result of the action of the syringe driver. The larger the concentration of surfactant included within the formulation, the greater the energy the liposome as a whole is be able to retain [65]. It is postulated that this energy is used to reorientate the lipid bilayer structure, and since all systems tend toward the lowest state of free energy, the energy stored in this structure will be expelled once the liposome has passed through the pore and there is no longer any pressure forcing the bilayer to remain in an 'unnatural state' $[35,36,66]$. This energy can then be expended into reforming the liposome. Some energy will be lost during passage as heat or non-plastic deformation, therefore it was not possible to attain a DI of $0 \%$.

The energy used to alter the bilayer of a liposome containing no surfactant does not benefit from the extra 'storage space' of a surfactant, thus energy may be expended to rupture the membrane causing liposome size to decrease [65]. Despite the potential for excess energy in liposomes formulated with Tween 20, liposomes were not able to fully regain their preextrusion size. Some energy will always be lost in the friction of the particles moving through the pores as heat [67]. An increase in surfactant loading may bring the liposomes closer to $100 \%$ reformation [65]. Further, liposomes unable to fit through the pores or lipid aggregates from ruptured liposomes may cause blockages. This may lead to an increase in pressure in the vessel causing more turbulence leading to the rupture and non-uniform reformation of liposomes. Additionally, in-vivo, liposomes would be expected to move across the skin following an osmotic transepidermal gradient as has been reported in many similar studies 
concerning the dermal and transdermal delivery of drug $[64,39,65,32]$. Such lipid carriers are miscible with the epidermal lipids present within the barrier of the stratum corneum thus would be able to penetrate into deeper layers of the skin [68-70]. Furthermore, the skin is warmer than room temp $\left(35^{\circ} \mathrm{C}\right.$ compared to $\left.20^{\circ} \mathrm{C}\right)$. Temperature governs the energy term of enthalpy therefore the liposomes would have more energy to be even more flexible and cross the stratum corneum. M.

\subsection{Differential scanning calorimetry investigations of EGCG and EGCG lipid blends}

Differential scanning calorimetry (DSC) has been widely used in understanding the thermal characteristics of materials where an insight into a range of thermal properties including melting temperatures, phase transitions and heat capacity changes can be obtained. It has been observed that drugs with melting point of $<200{ }^{\circ} \mathrm{C}$ are better poised to cross the SC $[71,24]$, therefore observing the effect of formulation parameters on the melting point would aid formulation development. The glass transition temperature $\left(T_{c}\right)$ of EGCG was identified at $220{ }^{\circ} \mathrm{C}$ (peak c) and the melting point $\left(\mathrm{T}_{\mathrm{m}}\right)$ of EGCG was at $245{ }^{\circ} \mathrm{C}$ (peak d) (Figure 4) and concurred with those reported by Cho et al (2008) where the $T_{m}$ of GCG (an epimer of EGCG) was at $223{ }^{\circ} \mathrm{C}$, the $\mathrm{T}_{\mathrm{c}}$ of EGCG was at $235^{\circ} \mathrm{C}$ and the $\mathrm{T}_{\mathrm{m}}$ of EGCG was at $246{ }^{\circ} \mathrm{C}$. Cho et al also observed a peak at $97{ }^{\circ} \mathrm{C}$ and determined it to be the conversion temperature of EGCG into GCG. Therefore, the first two troughs (peak a and b) observed in the scan may be representative of the epimer GCG [72].

\section{[Figure 4 near here]}

The DSC of the lipid (PC and cholesterol) and Tween 20 blend observed the $\mathrm{T}_{\mathrm{m}}$ of this mixture to be $172{ }^{\circ} \mathrm{C}$ (Figure 5A). Upon addition of EGCG to this mixture, the melting point shifted to $191{ }^{\circ} \mathrm{C}$ (Figure 5B), illustrating that the surfactant loaded liposomes could decrease the $T_{m}$ of EGCG thus potentially improving partitioning across the skin [73]. 
397

398

399

400

401

402

403

404

405

406

407

408

409

410

411

412

413

414

415

416

417

418

419

420

[Figure 5 near here]

\subsection{EGCG release studies from liposomal formulations}

The release of EGCG from solution and liposomal formulations was studied over a 24-hour period (Figure 6). Liposomes appeared to retard the release of EGCG in comparison to release across the membrane from EGCG in solution. Furthermore, with increasing the loading of Tween 20 within liposomal formulations ( 0 to $10 \% \mathrm{w} / \mathrm{w}$ ), EGCG release increased from $13.65 \pm 1.12 \%$ at 24 hours for $0 \% \mathrm{w} / \mathrm{w}$ Tween 20 , to $94.37 \pm 4.90 \%$ at 24 hours for $10 \% \mathrm{w} / \mathrm{w}$ Tween 20 . The cumulative percentage released after 24 hours was significant between the solution and liposomes loaded with $0 \%, 2 \%$, and $6 \% \mathrm{w} / \mathrm{w}$ of Tween $20(\mathrm{P} \leq 0.0001)$. The inclusion of surfactant enables an increase in drug solubility of poorly soluble compounds thus explaining the increase in drug release at higher loadings of surfactant. Such properties are already exploited to improve the oral delivery release profiles of poorly soluble compounds in self-emulsifying drug delivery systems with four drug products $[74,75]$, Sandimmune ${ }^{\circledR}$ and Sandimmun Neoral ${ }^{\circledR}$ (cyclosporin A), Norvir $\AA$ (ritonavir), and Fortovase ${ }^{\circledR}$ (saquinavir) on the pharmaceutical market [74]. It is worth noting that as surfactant loading increased, EGCG entrapment decreased thus a lower concentration gradient would be observed. This did not appear to retard EGCG release.

[Figure 6 near here]

An increased rate of release was observed from the EGCG solution compared with liposome formulations over the 24 hours observed (Table 2). Further, as the loading of surfactant increased, the rate of EGCG release increased (from $0.034 \pm 0.013$ to $0.993 \pm$ 1.013 for liposomes loaded with $0 \%$ and $10 \%$ of Tween 20 respectively based on the Korsmeyer-Peppas model). Thus, surfactant appears to increase drug release, particularly at $10 \% \mathrm{w} / \mathrm{w}$ where the rate was 10 fold greater than that at $6 \% \mathrm{w} / \mathrm{w}$. The surfactant would 
421 increase drug solubility thus explaining why an increase in drug release is observed at higher

422 loadings of surfactant. The inclusion of surfactant destabilizes the vesicle bilayers by

423 reducing the amount of work required to expand the interface allowing the liposome to

424 become more flexible $[40,38,39]$ and move through the membrane. Additionally, it has been

425 suggested that the mechanism of the in-vitro release seems to be the formation of transient

426 pores in the lipid bilayer, through which drugs are released to the extra-liposomal medium

427 (Wang, Wang et al. 2016).

$428 \quad$ [Table 2 near here]

Based on the values of the determination coefficient $\left(\mathrm{R}^{2}\right)$, as well as AIC values 430 (Akaike Information Criterion), the model that best describes EGCG release from all 431 liposomal formulations is Korsmeyer-Peppas model (highest $\mathrm{R}^{2}$ and lowest AIC). The 432 diffusion release exponent value revealed a range of release mechanisms for each 433 formulation. Liposomes formulated with $0 \%, 6 \%$ and $10 \% \mathrm{w} / \mathrm{w}$ Tween 20 had an exponent 434 value of $0.839 \pm 0.072,0.836 \pm 0.116$ and $0.722 \pm 0.247$ respectively indicating the release is 435 a complex mixture of the diffusion (flux due to molecular diffusion and the concentration 436 gradient) and erosion controlled drug release or class-II kinetics (diffusion not based on 437 concentration gradient) processes and often termed anomalous transport [76]. Liposomes 438 formulated with $2 \% \mathrm{w} / \mathrm{w}$ Tween 20 observed an exponent value of $0.913 \pm 0.186$ indicative 439 of erosion controlled drug release or class-II kinetics [48].

\subsection{Stability of EGCG loaded deformable liposomes}

The impact of long-term storage of EGCG-loaded liposomes formulated with $2 \%$ $442 \mathrm{w} / \mathrm{w}$ Tween 20 was assessed during storage in stability cabinets maintained at $25 \pm 2{ }^{\circ} \mathrm{C}$ 443 (Firlabo, France) at a humidity of $60 \% \pm 5 \%$. Liposomes formulated with $2 \% \mathrm{w} / \mathrm{w}$ Tween 444 were selected in this study as it had the highest EGCG entrapment compared with the higher 
445 loadings of surfactant thus will be taken forward for cell uptake studies. The impact of this 446 storage on size (Figure 7) and encapsulation efficiency (Figure 8) was assessed. EGCG 447 loaded liposomes formulated with and without surfactant maintained a consistent size over 448 time (Figure 7) with no statistically significant difference in size during the storage period. 449 Previous reports have highlighted that aggregation is common upon liposomal formulation 450 storage, and results in vesicle size growth [77] particularly with neutral liposomes [56]. 451 However, the inclusion of Tween 20 into the deformable liposomes may have prevented this 452 phenomenon and may be a result of surfactant destabilising the lipid bilayer and reducing the 453 energy required to expand the interface, thus allowing maintenance of smaller structures. It 454 appears the inclusion of surfactant prevents this phenomenon which correlates with similar 455 studies [78].

$456 \quad$ [Figure 7 and 8 near here]

457 Furthermore, encapsulation efficiency appears to decrease non-significantly from $43.02 \pm$ $4586.82 \%$ to $42.29 \pm 11.63 \%, 38.76 \pm 9.08 \%, 30.38 \pm 11.18 \%$ to $30.33 \pm 6.42 \%$, for 459 liposomes formulated with $2 \% \mathrm{w} / \mathrm{w}$ Tween 20 (Figure 8). This suggests drug leaching is 460 independent of surfactant loading. However, Tween 20 is able to increase compound 461 solubility, therefore, as not all would be entrapped within the bilayer, this may allow EGCG 462 to solubilise within the liposomal media [60]. Therefore, as the loading of Tween 20 463 increased, this would increase the amount of free Tween 20 resulting in more EGCG being 464 able to solubilise in the liposome media. 
467 Whilst topical formulations are applied directly into the skin, various connective layers 468 making up the skin are important for drug delivery. The skin primarily consists of the 469 epidermis, dermis and subcutaneous layers and each layer has a unique combination of cells, 470 connective tissue, components and functions. Skin cancers develop in the upper layers of the 471 skin spanning the dermal and epidermal layer, and any formulation system should consider 472 the impact of formulation systems on these tissue layers for the delivery of drugs.

473 In order to assess cellular toxicity of EGCG to these cells, we adopted two in-vitro cell 474 culture systems, namely human keratinocyte and human fibroblast cells. To determine the 475 cellular viability cytotoxicity of EGCG towards HDFa and HaCat cells, an XTT assay was 476 performed to measure cell death after exposure of cells to different concentrations of drug for 47724 hours (Figure 9).

$478 \quad$ [Figure 9 near here]

479 As the concentration of EGCG was increased from 0.1 to $100 \mu \mathrm{M}$, HDFa cell viability 480 decreased (Figure 9A) with statistical significance $(\mathrm{P} \leq 0.0001)$. This may be due to toxicity 481 or death of damaged cells in which EGCG induced apoptosis [79, 80]. Whilst limited data 482 exists on the cytotoxicity of EGCG towards dermal tissues, a study observing growth 483 inhibition in multiple cell lines, observed that EGCG at $40 \mu \mathrm{M}$ had little or no inhibitory 484 effect on the growth of WI38 cells, normal human fibroblast cells [81]. Cell viability was 485 maintained across the concentration range of $0.1-100 \mu \mathrm{M}$ on HaCat cells (Figure 9B). No 486 statistically significant difference was observed in cell viability $(P \geq 0.05)$. Furthermore, 487 EGCG has been reported to impart protective effects in HaCat cells exposed to external 488 stressors including UVA and UVB radiation [82, 83]. Whilst some of our formulations exceeded this concentration of EGCG as a whole, the retarded release profile of the 
490 liposomes would be expected to result in an overall lower temporal concentration profile

491 exposure to these cells, significantly below $100 \mu \mathrm{M}$.

492

493

494

495

496

497

498

499

500

501

502

503

504

505

506

507

508

509

510

511

512

513

\subsection{Cellular liposomal uptake assay into HDFa and HaCat cells}

A primary goal for our studies was to demonstrate uptake of deformable liposomes loaded with EGCG into a cell culture skin model. EGCG loaded liposomes were incubated with both HaCat (Figure 10) and HDFa (Figure 11) cells to assess the cellular uptake of these formulations. Liposomes formulated with $2 \% \mathrm{w} / \mathrm{w}$ Tween 20 were selected, a result of the highest EGCG entrapment compared with the other surfactant loadings. DilC labelled liposomes loaded with EGCG incubated for 2-hours with both HaCat and HDFa cells seeded onto collagen-coated coverslips and the cellular localisation of these liposomes was determined using confocal microscopy. Following a 2-hour incubation with the cells, intracellular localisation of labelled liposomes were clearly evident, confirming the successful uptake into both HaCat and HDFa cells.

[Figure 10 and 11 near here]

Extraneous particle cell uptake is dependent upon influences such as particle size, charge, affinity etc. [84-86]. There are four proposed methods of liposome uptake into cells: stable adsorption, endocytosis, fusion of the lipid bilayer with the cell plasma membrane and lipid transfer [43, 87]. It is unclear which of these occurred in this study, however, these methods of uptake are not mutually exclusive and any combination may occur in a given experimental circumstance [43]. The interaction of nanoparticles with cell membrane seems to be most affected by particle surface charge. The cell membrane surface is dominated by negatively charged sulphated proteoglycans molecules (vital in cellular proliferation and migration) $[88,89]$. These molecules are associated with glycosaminoglycan side chains (heparan, dermatan, keratan or chondrotine sulfates) which are anionic, and interaction 
514 between proteoglycans and liposomes, if positively charged, tend to be largely ionic [90]. The

515 liposomes applied to the cells in this study had a $\zeta$ of $3.67 \pm 0.91$ suggesting an ionic

516 interaction may have occurred. A study applying cationic liposomes formulated with the

517 cationic lipids Lipofectin, Tfx-50, and Lipofectamine in oligonucleotide delivery to HaCat

518 cells observed liposome uptake within 24 hours [91]. Furthermore, research developing

519 chemotherapy against malignant melanoma using mouse B16 melanoma cells as well as

520 Normal Human Dermal Fibroblasts observed a greater uptake of cationic liposomes by cells

521 in the injection site compared with neutral liposomes due to the electrostatic interaction with

522 the negative-charged phospholipid membrane of cells [92].

523 It should be noted that the confocal microscopy studies demonstrated the possibility of the

524 delivery of deformable liposomes to relevant dermal tissues using in-vitro cell culture

525 techniques. However, the application of such formulations could also be assessed using ex-

526 vivo human or animal dermal tissues. The ultimate aim of this delivery system was to

527 improve dermal cell uptake and delivery a controlled release of active agent, thus from a

528 regulatory perspective, pharmacokinetic data is not required as drug is not intended to reach

529 the blood stream [93].

530 In order to ascertain the extent of carrier and drug permeation a skin strip test may be

531 appropriate [70]. This involves the use of an adhesive tape to strip the skin layer by layer and

532 quantifying lipid and drug on each layer[94]. Further, whilst the most appropriate animal

533 model for human skin is the porince skin tissue, sample-to-sample variability in addition to

534 differences in the lipid dermal matrices often results in an altered permeability profile

535 limiting the wider human translational goals [95-97].

536 4. Conclusion 
Skin cancer is emerging as an increasing public health problem particularly in developed countries. Current treatments include surgery to remove the tumour as well as topical formulations. Such treatments may not be suitable for all patients as they are associated with an unpleasant aesthetic profile as well as side effects. A nanoparticle delivery system such as deformable liposomes applied topically for the direct dermal delivery of compounds would be valuable in carrying compounds across the stratum corneum at a controlled rate whilst limiting side effects. The use of naturally occurring compounds such as EGCG have been found to be successful as chemopreventative and chemoprotective agents. However, formulation of such compounds has been limited in success due to a limited bioavailability of promising agents and inefficient delivery systems. We developed a novel deformable liposome formulation loaded with EGCG and systemically investigated the loading, uptake and in-vitro release of EGCG from these nanoparticles. This study has found deformable liposomes could be valuable in enhancing the bioavailability of these compounds as well as offering controlled release of the compound [13, 98]. We have demonstrated that as the amount of Tween 20 in the liposomal bilayer is increased, liposome size decreased and elasticity increased. As the loading of Tween 20 in the liposome was increased the EGCG encapsulation decreased. This may have been due to Tween 20 competing for space within the bilayer or due to Tween 20 increasing the solubilisation capacity of EGCG. Additionally EGCG release from liposomes found that the liposomes were able to modify the release of drug with complete release observed within 24 hours. Further, our studies demonstrated these liposomes were capable of uptake into epidermal keratinocytes and dermal fibroblasts within 2 hours. This present study demonstrates liposomes formulated with Tween 20 are useful in enhancing drug penetration into dermal cells and in the development of a controlled release formulation crucial in improving patient compliance thus skin cancer treatment outcomes. 
562 The authors report no conflict of interest.

\section{References}

564 1. Lomas A, Leonardi-Bee J, Bath-Hextall F. A systematic review of worldwide incidence of

565 nonmelanoma skin cancer. The British journal of dermatology. 2012;166(5):1069-80. 566 doi:10.1111/j.1365-2133.2012.10830.x.

567 2. World Health Organisation. Ultraviolet radiation (UV): Skin cancers. 2017. 568 http://www.who.int/uv/faq/skincancer/en/index1.html. Accessed 20/11/2017 2017.

569 3. Diepgen TL, Mahler V. The epidemiology of skin cancer. The British journal of 570 dermatology. 2002;146 Suppl 61(s61):1-6.

571 4. Donaldson MR, Coldiron BM, editors. No end in sight: the skin cancer epidemic 572 continues. Seminars in cutaneous medicine and surgery; 2011: Frontline Medical 573 Communications.

574 5. American Cancer Society. Cancer Facts and Figures. 2017.

575 http://www.cancer.org/acs/groups/content/@editorial/documents/document/acspc-

$576 \quad$ 048738.pdf. Accessed 10/01/2017 2017.

577 6. Ali SM, Brodell RT, Balkrishnan R, Feldman SR. Poor adherence to treatments: A 578 fundamental principle of dermatology. Archives of dermatology. 2007;143(7):912-5. 579 doi:10.1001/archderm.143.7.912.

580 7. Felicio L, Ferreira J, Kurachi C, Bentley M, Tedesco A, Bagnato V. Long-term follow-up 581 of topical 5-aminolaevulinic acid photodynamic therapy diode laser single session for non582 melanoma skin cancer. Photodiagnosis and photodynamic therapy. 2009;6:207-13.

583 8. Kaplan B, Moy RL. Effect of perilesional injections of PEG-interleukin-2 on basal cell 584 carcinoma. Dermatol Surg. 2000;26(11):1037-40. 
585 9. Neville JA, Welch E, Leffell DJ. Management of nonmelanoma skin cancer in 2007. Nat 586 Clin Prac Oncol. 2007;4(8):462-9.

587 10. Bansal T, Jaggi M, Khar R, Talegaonkar S. Emerging significance of flavonoids as P588 glycoprotein inhibitors in cancer chemotherapy. Journal of Pharmacy \& Pharmaceutical 589 Sciences. 2009;12(1):46-78.

590 11. Kanadaswami C, Lee L-T, Lee P-PH, Hwang J-J, Ke F-C, Huang Y-T et al. The 591 antitumor activities of flavonoids. In Vivo. 2005;19(5):895-909.

592 12. Carey MP, Burish TG. Etiology and treatment of the psychological side effects associated 593 with cancer chemotherapy: A critical review and discussion. Psychological bulletin. $594 \quad 1988 ; 104(3): 307$.

595 13. Siddiqui IA, Adhami VM, Bharali DJ, Hafeez BB, Asim M, Khwaja SI et al. Introducing 596 Nanochemoprevention as a Novel Approach for Cancer Control: Proof of Principle with 597 Green Tea Polyphenol Epigallocatechin-3-Gallate. Cancer research. 2009;69(5):1712-6. 598 doi:10.1158/0008-5472.can-08-3978.

599 14. Hwang J-T, Ha J, Park I-J, Lee S-K, Baik HW, Kim YM et al. Apoptotic effect of EGCG 600 in HT-29 colon cancer cells via AMPK signal pathway. Cancer letters. 2007;247(1):115-21. 601 doi:http://dx.doi.org/10.1016/j.canlet.2006.03.030.

602 15. Singh BN, Shankar S, Srivastava RK. Green tea catechin, epigallocatechin-3-gallate 603 (EGCG): Mechanisms, perspectives and clinical applications. Biochemical pharmacology. 604 2011;82(12):1807-21. doi:http://dx.doi.org/10.1016/j.bcp.2011.07.093.

605 16. Casey SC, Amedei A, Aquilano K, Azmi AS, Benencia F, Bhakta D et al. Cancer 606 prevention and therapy through the modulation of the tumor microenvironment. Seminars in 607 cancer biology. 2015. doi:10.1016/j.semcancer.2015.02.007. 
608

609

610

611

612

613

614

615

616

617

618

619

620

621

622

623

624

625

626

627

628

629

630

631

632

17. Gupta S, Hastak K, Afaq F, Ahmad N, Mukhtar H. Essential role of caspases in epigallocatechin-3-gallate-mediated inhibition of nuclear factor kappa $\mathrm{B}$ and induction of apoptosis. Oncogene. 2004;23(14):2507-22. doi:10.1038/sj.onc.1207353.

18. Singh T, Vaid M, Katiyar N, Sharma S, Katiyar SK. Berberine, an isoquinoline alkaloid, inhibits melanoma cancer cell migration by reducing the expressions of cyclooxygenase-2, prostaglandin $\mathrm{E}(2)$ and prostaglandin $\mathrm{E}(2)$ receptors. Carcinogenesis. 2011;32(1):86-92. doi:10.1093/carcin/bgq215.

19. Thawonsuwan J, Kiron V, Satoh S, Panigrahi A, Verlhac V. Epigallocatechin-3-gallate (EGCG) affects the antioxidant and immune defense of the rainbow trout, Oncorhynchus mykiss. Fish physiology and biochemistry. 2010;36(3):687-97. doi:10.1007/s10695-0099344-4.

20. Sigler K, Ruch RJ. Enhancement of gap junctional intercellular communication in tumor promoter-treated cells by components of green tea. Cancer letters. 1993;69(1):15-9.

21. Basnet P, Hussain H, Tho I, Skalko-Basnet N. Liposomal delivery system enhances antiinflammatory properties of curcumin. J Pharm Sci. 2012;101(2):598-609. doi:10.1002/jps.22785.

22. Wang Y, Wang S, Firempong CK, Zhang H, Wang M, Zhang Y et al. Enhanced Solubility and Bioavailability of Naringenin via Liposomal Nanoformulation: Preparation and In Vitro and In Vivo Evaluations. Aaps Pharmscitech. 2016. doi:10.1208/s12249-016$0537-8$.

23. Zhao Y-Z, Lu C-T, Zhang Y, Xiao J, Zhao Y-P, Tian J-L et al. Selection of high efficient transdermal lipid vesicle for curcumin skin delivery. Int J Pharmaceut. 2013;454(1):302-9.

24. Alexander A, Dwivedi S, Giri TK, Saraf S, Saraf S, Tripathi DK. Approaches for breaking the barriers of drug permeation through transdermal drug delivery. J Control Release. 2012;164(1):26-40. 
633 25. Lopez RF, Seto JE, Blankschtein D, Langer R. Enhancing the transdermal delivery of 634 rigid nanoparticles using the simultaneous application of ultrasound and sodium lauryl 635 sulfate. Biomaterials. 2011;32(3):933-41. doi:10.1016/j.biomaterials.2010.09.060.

636 26. Tsai MJ, Huang YB, Fang JW, Fu YS, Wu PC. Preparation and Characterization of 637 Naringenin-Loaded Elastic Liposomes for Topical Application. PloS one. 638 2015;10(7):e0131026. doi:10.1371/journal.pone.0131026.

639 27. Alexander A, Dwivedi S, Ajazuddin, Giri TK, Saraf S, Saraf S et al. Approaches for 640 breaking the barriers of drug permeation through transdermal drug delivery. J Control 641 Release. 2012;164(1):26-40. doi:DOI 10.1016/j.jconrel.2012.09.017.

642 28. Bouwstra JA, Honeywell-Nguyen PL. Skin structure and mode of action of vesicles. Adv 643 Drug Deliv Rev. 2002;54 Suppl 1:S41-55.

644 29. du Plessis J, Weiner N, Müller D. The influence of in vivo treatment of skin with 645 liposomes on the topical absorption of a hydrophilic and a hydrophobic drug in vitro. Int $\mathrm{J}$ 646 Pharmaceut. 1994;103(2):R1-R5.

647 30. Park S-I, Lee E-O, Yang H-M, Park CW, Kim J-D. Polymer-hybridized liposomes of 648 poly (amino acid) derivatives as transepidermal carriers. Colloids and Surfaces B: 649 Biointerfaces. 2013;110:333-8.

650 31. Cevc G, Gebauer D, Stieber J, Schätzlein A, Blume G. Ultraflexible vesicles, 651 Transfersomes, have an extremely low pore penetration resistance and transport therapeutic 652 amounts of insulin across the intact mammalian skin. Biochimica et Biophysica Acta (BBA) 653 Biomembranes. 1998;1368(2):201-15. doi:http://dx.doi.org/10.1016/S0005-2736(97)00177$654 \underline{6}$.

655 32. Goindi S, Kumar G, Kumar N, Kaur A. Development of novel elastic vesicle-based 656 topical formulation of cetirizine dihydrochloride for treatment of atopic dermatitis. Aaps 657 Pharmscitech. 2013;14(4):1284-93. doi:10.1208/s12249-013-0017-3. 
658 33. El MGMM, C. WA, W. BB. Skin delivery of 5-fluorouracil from ultradeformable and 659 standard liposomes in-vitro. J Pharm Pharmacol. 2001;53(8):1069-77. 660 doi:doi:10.1211/0022357011776450.

661 34. Cevc GS, A.; Gebauer, D.; Blume, G. Ultra-high efficiency of drug and peptide transfer 662 through the intact skin by means of novel drug-carriers, Transfersomes. In: Bain KRH, J.; 663 James, W.J.; Water, K.A., editor. Prediction of Percutaneous Penetration. Cardiff: STS 664 Publishing; 1993. p. 226-34.

665 35. Cevc G, Schätzlein A, Gebauer D, Blume G. Ultra-high efficiency of drugs and peptide 666 transfer through the intact skin by means of novel drug carriers, transfersomes. STS 667 Publishing; 1993.

668 36. Cevc G. Material transport across permeability barriers by means of lipid vesicles. 669 Handbook of biological physics. 1995;1:465-90.

670 37. Romero EL, Morilla MJ. Highly deformable and highly fluid vesicles as potential drug 671 delivery systems: theoretical and practical considerations. Int J Nanomedicine. 2013;8:3171672 86. doi:10.2147/ijn.s33048.

673 38. Oh YK, Kim MY, Shin JY, Kim TW, Yun MO, Yang SJ et al. Skin permeation of retinol 674 in Tween 20-based deformable liposomes: in-vitro evaluation in human skin and keratinocyte 675 models. J Pharm Pharmacol. 2006;58(2):161-6. doi:10.1211/jpp.58.2.0002.

676 39. Cevc G. Transfersomes, liposomes and other lipid suspensions on the skin: permeation 677 enhancement, vesicle penetration, and transdermal drug delivery. Crit Rev Ther Drug Carrier 678 Syst. 1996;13(3-4):257-388.

679 40. Ita KB, Du Preez J, Lane ME, Hadgraft J, du Plessis J. Dermal delivery of selected 680 hydrophilic drugs from elastic liposomes: effect of phospholipid formulation and surfactants. 681 J Pharm Pharmacol. 2007;59(9):1215-22. doi:10.1211/jpp.59.9.0005. 
682

683

684

685

686

687

688

689

690

691

692

693

694

695

696

697

698

699

700

701

702

703

704

41. Bangham AD, Standish MM, Watkins JC. Diffusion of univalent ions across the lamellae of swollen phospholipids. Journal of molecular biology. 1965;13(1):238-52.

42. Hiruta Y, Hattori Y, Kawano K, Obata Y, Maitani Y. Novel ultra-deformable vesicles entrapped with bleomycin and enhanced to penetrate rat skin. J Control Release. 2006;113(2):146-54. doi:http://dx.doi.org/10.1016/j.jconrel.2006.04.016.

43. Pagano RE, Weinstein JN. Interactions of liposomes with mammalian cells. Annual review of biophysics and bioengineering. 1978;7(1):435-68.

44. Ali MH, Moghaddam B, Kirby DJ, Mohammed AR, Perrie Y. The role of lipid geometry in designing liposomes for the solubilisation of poorly water soluble drugs. Int J Pharmaceut. 2013;453(1):225-32. doi:DOI 10.1016/j.ijpharm.2012.06.056.

45. Lasic DD, Barenholz Y. Handbook of nonmedical applications of liposomes: Theory and basic sciences. CRC Press; 1996.

46. Song Y-K, Kim C-K. Topical delivery of low-molecular-weight heparin with surfacecharged flexible liposomes. Biomaterials. 2006;27(2):271-80. doi:http://dx.doi.org/10.1016/j.biomaterials.2005.05.097.

47. Bradfield A, Penney M. 456. The catechins of green tea. Part II. Journal of the Chemical Society (Resumed). 1948:2249-54.

48. Korsmeyer RW, Gurny R, Doelker E, Buri P, Peppas NA. Mechanisms of solute release from porous hydrophilic polymers. Int $\mathrm{J}$ Pharmaceut. 1983;15(1):25-35. doi:http://dx.doi.org/10.1016/0378-5173(83)90064-9.

49. Scudiero DA, Shoemaker RH, Paull KD, Monks A, Tierney S, Nofziger TH et al. Evaluation of a soluble tetrazolium/formazan assay for cell growth and drug sensitivity in culture using human and other tumor cell lines. Cancer research. 1988;48(17):4827-33. 
705

706

707

708

709

710

711

712

713

714

715

716

717

718

719

720

721

722

723

724

725

726

727

728

729

50. Yang CS, Maliakal P, Meng X. Inhibition of carcinogenesis by tea. Annual review of pharmacology and toxicology.

$2002 ; 42: 25-54$ doi:10.1146/annurev.pharmtox.42.082101.154309.

51. McLoughlin P, Roengvoraphoj M, Gissel C, Hescheler J, Certa U, Sachinidis A. Transcriptional responses to epigallocatechin-3 gallate in HT 29 colon carcinoma spheroids. Genes to cells : devoted to molecular \& cellular mechanisms. 2004;9(7):661-9. doi:10.1111/j.1356-9597.2004.00754.x.

52. El Zaafarany GM, Awad GA, Holayel SM, Mortada ND. Role of edge activators and surface charge in developing ultradeformable vesicles with enhanced skin delivery. Int $\mathrm{J}$ Pharmaceut. 2010;397(1):164-72.

53. Chen Y, Wu Q, Zhang Z, Yuan L, Liu X, Zhou L. Preparation of curcumin-loaded liposomes and evaluation of their skin permeation and pharmacodynamics. Molecules. 2012;17(5):5972-87. doi:10.3390/molecules 17055972.

54. Kang SN, Hong S-S, Kim S-Y, Oh H, Lee M-K, Lim S-J. Enhancement of liposomal stability and cellular drug uptake by incorporating tributyrin into celecoxib-loaded liposomes. Asian Journal of Pharmaceutical Sciences. 2013;8(2):128-33. doi:http://dx.doi.org/10.1016/j.ajps.2013.07.016.

55. Prausnitz MR, Langer R. Transdermal drug delivery. Nat Biotech. 2008;26(11):1261-8.

56. Weiner N, Egbaria K, Ramachandran C. Topical Delivery of Liposomally Encapsulated Interferon Evaluated by In Vitro Diffusion Studies and in a Cutaneous Herpes Guinea Pig Model. In: Braun-Falco O, Korting HC, Maibach HI, editors. Liposome Dermatics: Griesbach Conference. Berlin, Heidelberg: Springer Berlin Heidelberg; 1992. p. 242-50.

57. El Maghraby GMM, Williams AC, Barry BW. Oestradiol skin delivery from ultradeformable liposomes: refinement of surfactant concentration. Int $\mathrm{J}$ Pharmaceut. 2000;196(1):63-74. doi:http://dx.doi.org/10.1016/S0378-5173(99)00441-X. 
730 58. Levy MY, Benita S, Baszkin A. Interactions of a non-ionic surfactant with mixed

731 phospholipid —oleic acid monolayers. Studies under dynamic conditions. Colloid Surface.

732 1991;59:225-41. doi:http://dx.doi.org/10.1016/0166-6622(91)80249-N.

733 59. Casas M, Baszkin A. Interactions of a non-ionic surfactant with mixed phospholipid-

734 oleic acid monolayers. Surface potential and surface pressure studies at constant area. Colloid

735 Surface. 1992;63(3):301-9. doi:http://dx.doi.org/10.1016/0166-6622(92)80252-W.

736 60. Almog S, Kushnir T, Nir S, Lichtenberg D. Kinetic and structural aspects of

737 reconstitution of phosphatidylcholine vesicles by dilution of phosphatidylcholine-sodium

738 cholate mixed micelles. Biochemistry. 1986;25(9):2597-605.

739 61. Almog S, Kushnir T, Nir S, Lichtenberg D. Kinetic and structural aspects of 740 reconstitution of phosphatidylcholine vesicles by dilution of phosphatidylcholine-sodium 741 cholate mixed micelles. Biochemistry. 1986;25(9):2597-605.

742 62. Trotta M, Peira E, Carlotti ME, Gallarate M. Deformable liposomes for dermal 743 administration of methotrexate. Int J Pharm. 2004;270(1-2):119-25.

744 63. Fresta M, Puglisi G. Application of liposomes as potential cutaneous drug delivery 745 systems. In vitro and in vivo investigation with radioactively labelled vesicles. J Drug Target. 746 1996;4(2):95-101. doi:10.3109/10611869609046267.

747 64. Gompper G, Kroll DM. Driven transport of fluid vesicles through narrow pores. Physical 748 review E, Statistical physics, plasmas, fluids, and related interdisciplinary topics. 749 1995;52(4):4198-208.

750 65. Trotta M, Peira E, Debernardi F, Gallarate M. Elastic liposomes for skin delivery of 751 dipotassium glycyrrhizinate. Int J Pharmaceut. 2002;241(2):319-27. 752 doi:http://dx.doi.org/10.1016/S0378-5173(02)00266-1.

753 66. Chung H, Caffrey M. The curvature elastic-energy function of the lipid-water cubic 754 mesophase. Nature. 1994;368(6468):224-6. doi:10.1038/368224a0. 
755

756

757

758

759

760

761

762

763

764

765

766

767

768

769

770

771

772

773

774

775

776

777

778

779

67. Vajjha RS, Das DK, Kulkarni DP. Development of new correlations for convective heat transfer and friction factor in turbulent regime for nanofluids. International Journal of Heat and Mass

Transfer. 2010;53(21):4607-18. doi:http://dx.doi.org/10.1016/j.ijheatmasstransfer.2010.06.032.

68. Kirjavainen M, Urtti A, Jääskeläinen I, Marjukka Suhonen T, Paronen P, ValjakkaKoskela $\mathrm{R}$ et al. Interaction of liposomes with human skin in vitro - The influence of lipid composition and structure. Biochimica et Biophysica Acta (BBA) - Lipids and Lipid Metabolism. 1996;1304(3):179-89. doi:http://dx.doi.org/10.1016/S0005-2760(96)00126-9. 69. El Maghraby GM, Barry BW, Williams AC. Liposomes and skin: From drug delivery to model membranes. Eur J Pharm Sci. 2008;34(4-5):203-22. doi:http://dx.doi.org/10.1016/j.ejps.2008.05.002.

70. Schäfer-Korting M, Mehnert W, Korting H-C. Lipid nanoparticles for improved topical application of drugs for skin diseases. Adv Drug Deliver Rev. 2007;59(6):427-43. doi:http://dx.doi.org/10.1016/j.addr.2007.04.006.

71. Guy RH, Hadgraft J. Transdermal drug delivery: a simplified pharmacokinetic approach. Int J Pharmaceut. 1985;24(2-3):267-74.

72. Cho HH, Han D-W, Matsumura K, Tsutsumi S, Hyon S-H. The behavior of vascular smooth muscle cells and platelets onto epigallocatechin gallate-releasing poly(l-lactide-co- $\varepsilon$ caprolactone) as stent-coating materials. Biomaterials. 2008;29(7):884-93. doi:http://dx.doi.org/10.1016/j.biomaterials.2007.10.052.

73. Chu KA, Yalkowsky SH. An interesting relationship between drug absorption and melting point. Int J Pharm. 2009;373(1-2):24-40. doi:10.1016/j.ijpharm.2009.01.026.

74. Neslihan Gursoy R, Benita S. Self-emulsifying drug delivery systems (SEDDS) for improved oral delivery of lipophilic drugs. Biomedicine \& Pharmacotherapy. 2004;58(3):173-82. doi:https://doi.org/10.1016/j.biopha.2004.02.001. 
780

781

782

783

784

785

786

787

788

789

790

791

792

793

794

795

796

797

798

799

800

801

802

803

804

75. Vasconcelos T, Sarmento B, Costa P. Solid dispersions as strategy to improve oral bioavailability of poor water soluble drugs. Drug discovery today. 2007;12(23):1068-75. doi:https://doi.org/10.1016/j.drudis.2007.09.005.

76. Peppas NA, Sahlin JJ. A simple equation for the description of solute release. III. Coupling of diffusion and relaxation. Int $\mathrm{J}$ Pharmaceut. 1989;57(2):169-72. doi:http://dx.doi.org/10.1016/0378-5173(89)90306-2.

77. Lentz BR, Carpenter TJ, Alford DR. Spontaneous fusion of phosphatidylcholine small unilamellar vesicles in the fluid phase. Biochemistry. 1987;26(17):5389-97.

78. Seras M, Handjani-Vila R-M, Ollivon M, Lesieur S. Kinetic aspects of the solubilization of non-ionic monoalkyl amphiphile-cholesterol vesicles by octylglucoside. Chem Phys Lipids. 1992;63(1-2):1-14. doi:http://dx.doi.org/10.1016/0009-3084(92)90015-H.

79. Bae JY, Choi JS, Choi YJ, Shin SY, Kang SW, Han SJ et al. (-)Epigallocatechin gallate hampers collagen destruction and collagenase activation in ultraviolet-B-irradiated human dermal fibroblasts: involvement of mitogen-activated protein kinase. Food and chemical toxicology : an international journal published for the British Industrial Biological Research Association. 2008;46(4):1298-307. doi:10.1016/j.fct.2007.09.112.

80. Tanigawa T, Kanazawa S, Ichibori R, Fujiwara T, Magome T, Shingaki K et al. (+)Catechin protects dermal fibroblasts against oxidative stress-induced apoptosis. BMC complementary and alternative medicine. 2014;14:133. doi:10.1186/1472-6882-14-133.

81. Chen ZP, Schell JB, Ho C-T, Chen KY. Green tea epigallocatechin gallate shows a pronounced growth inhibitory effect on cancerous cells but not on their normal counterparts.

Cancer letters. 1998;129(2):173-9. doi:http://dx.doi.org/10.1016/S0304-3835(98)00108-6.

82. Huang C-C, Fang J-Y, Wu W-B, Chiang H-S, Wei Y-J, Hung C-F. Protective effects of (-)-epicatechin-3-gallate on UVA-induced damage in HaCaT keratinocytes. Archives of dermatological research. 2005;296(10):473-81. 
83. Huang C-C, Wu W-B, Fang J-Y, Chiang H-S, Chen S-K, Chen B-H et al. (-)-Epicatechin3-gallate, a green tea polyphenol is a potent agent against UVB-induced damage in $\mathrm{HaCaT}$ keratinocytes. Molecules. 2007;12(8):1845-58.

84. Patil S, Sandberg A, Heckert E, Self W, Seal S. Protein adsorption and cellular uptake of cerium oxide nanoparticles as a function of zeta potential. Biomaterials. 2007;28(31):4600-7. doi:10.1016/j.biomaterials.2007.07.029.

85. Chen C-C, Tsai T-H, Huang Z-R, Fang J-Y. Effects of lipophilic emulsifiers on the oral administration of lovastatin from nanostructured lipid carriers: Physicochemical characterization and pharmacokinetics. Eur J Pharm Biopharm. 2010;74(3):474-82. doi:https://doi.org/10.1016/j.ejpb.2009.12.008.

86. Kyung OY, Grabinski CM, Schrand AM, Murdock RC, Wang W, Gu B et al. Toxicity of amorphous silica nanoparticles in mouse keratinocytes. Journal of Nanoparticle Research. 2009;11(1):15-24.

87. Martin FJ, MacDonald RC. Lipid vesicle-cell interactions. I. Hemagglutination and hemolysis. The Journal of cell biology. 1976;70(3):494-505.

88. Merton Bernfield, Martin Götte, Pyong Woo Park, Ofer Reizes, Marilyn L. Fitzgerald, John Lincecum a et al. Functions of Cell Surface Heparan Sulfate Proteoglycans. Annual Review of Biochemistry. 1999;68(1):729-77. doi:10.1146/annurev.biochem.68.1.729.

89. Mislick KA, Baldeschwieler JD. Evidence for the role of proteoglycans in cationmediated gene transfer. Proceedings of the National Academy of Sciences. 1996;93(22):12349-54.

90. Panyam J, Labhasetwar V. Biodegradable nanoparticles for drug and gene delivery to cells and tissue. Adv Drug Deliv Rev. 2003;55(3):329-47.

91. White PJ, Fogarty RD, McKean SC, Venables DJ, Werther GA, Wraight CJ. Oligonucleotide Uptake in Cultured Keratinocytes: Influence of Confluence, Cationic 
830 Liposomes, and Keratinocyte Cell Type. J Invest Dermatol. 1999;112(5):699-705.

831 doi:https://doi.org/10.1046/j.1523-1747.1999.00578.x.

832 92. Ito A, Fujioka M, Yoshida T, Wakamatsu K, Ito S, Yamashita $\mathrm{T}$ et al. 4-S-

833 Cysteaminylphenol-loaded magnetite cationic liposomes for combination therapy of

834 hyperthermia with chemotherapy against malignant melanoma. Cancer science.

835 2007;98(3):424-30. doi:10.1111/j.1349-7006.2006.00382.x.

836 93. Products EAftEoM. Note for Guidance on the Investigation of Bioavailability and

837 Bioequivalence. London: European Agency for the Evaluation of Medicinal Products

$838 \quad 200014 / 12 / 2000$.

839 94. Weigmann H, Lademann J, Meffert H, Schaefer H, Sterry W. Determination of the horny

840 layer profile by tape stripping in combination with optical spectroscopy in the visible range as

841 a prerequisite to quantify percutaneous absorption. Skin Pharmacol Appl Skin Physiol.

$842 \quad$ 1999;12(1-2):34-45. doi:10.1159/000029844.

843 95. Schmook FP, Meingassner JG, Billich A. Comparison of human skin or epidermis models

844 with human and animal skin in in-vitro percutaneous absorption. Int $\mathrm{J}$ Pharmaceut.

$845 \quad 2001 ; 215(1-2): 51-6$.

846 96. Dick IP, Scott RC. Pig ear skin as an in - vitro model for human skin permeability. J

847 Pharm Pharmacol. 1992;44(8):640-5.

848 97. Godin B, Touitou E. Transdermal skin delivery: predictions for humans from in vivo, ex

849 vivo and animal models. Adv Drug Deliver Rev. 2007;59(11):1152-61.

850 98. Nishiyama N. Nanomedicine: Nanocarriers shape up for long life. Nat Nano. $851 \quad 2007 ; 2(4): 203-4$.

852 
854 Table 1: Zeta potential of liposomal formulations formulated in the absence and presence of 855 up to $10 \% \mathrm{w} / \mathrm{w}$ of Tween 20

\begin{tabular}{ccc}
\hline \multirow{2}{*}{$\begin{array}{c}\text { Surfactant } \\
\text { loading (\% w/w) }\end{array}$} & \multicolumn{2}{c}{ Zeta potential (mV) } \\
\cline { 2 - 3 } & 'empty' & EGCG loaded \\
& & liposomes \\
\hline $\mathbf{0}$ & $5.03 \pm 1.03$ & $2.41 \pm 1.08$ \\
$\mathbf{2}$ & $4.67 \pm 1.08$ & $3.67 \pm 0.91$ \\
$\mathbf{6}$ & $3.71 \pm 0.90$ & $-0.99 \pm 1.01$ \\
$\mathbf{1 0}$ & $-2.79 \pm 0.20$ & $-1.90 \pm 0.88$ \\
\hline
\end{tabular}

856 Results are presented as the mean \pm standard deviation $(\mathrm{n}=3)$ 
$n$
$n$
0
0
0
0
0
0
0

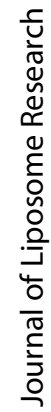

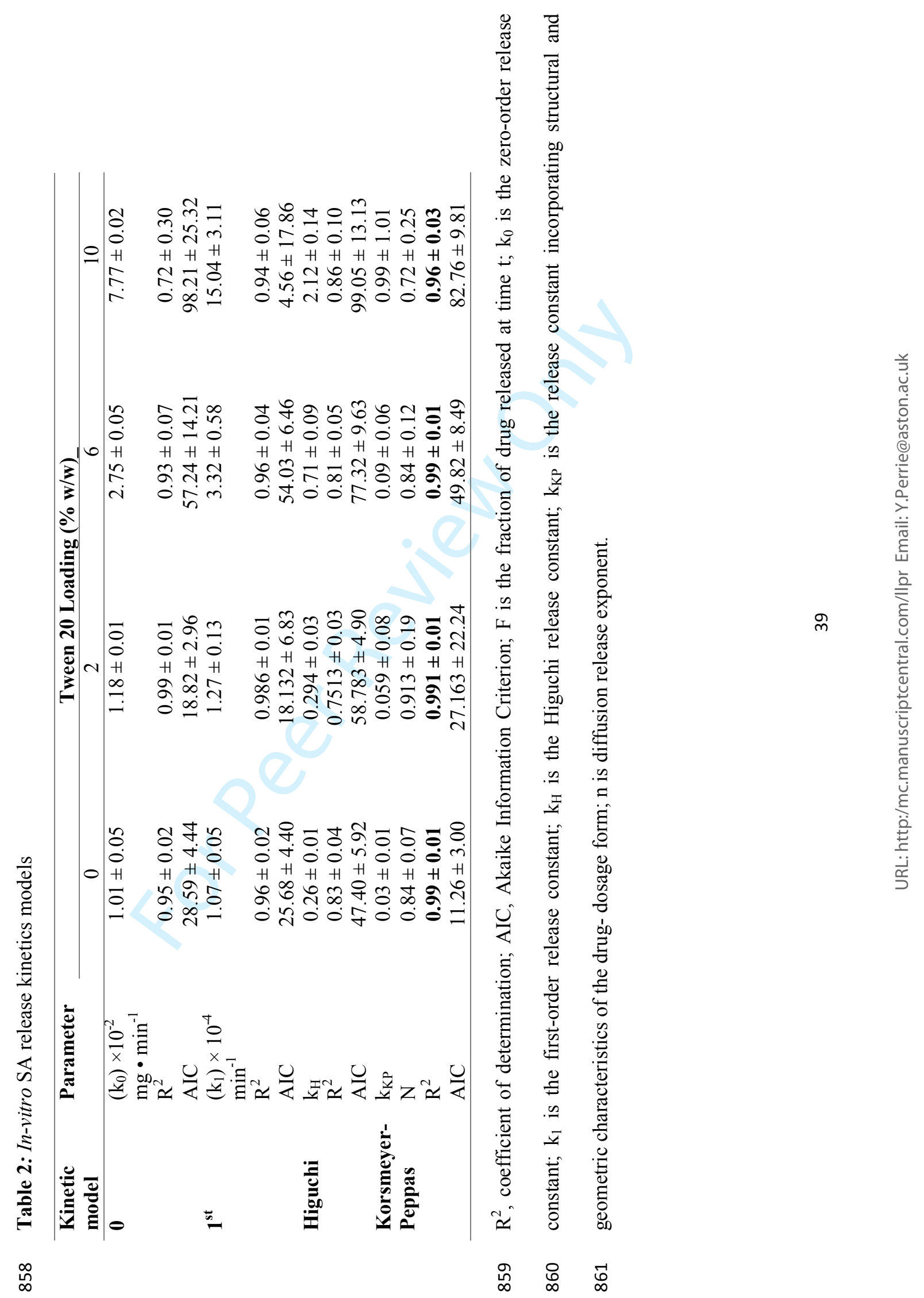

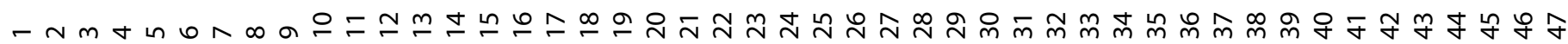


Fig. 1 Liposome size distribution and polydispersity of 'empty' and EGCG loaded liposomes

Liposome size distribution and polydispersity, determined by DLS, comparing (A) 'empty' and (B) EGCG loaded formulations with Tween $20(0-10 \% \mathrm{w} / \mathrm{w})$. Liposomes were prepared by the dry film hydration method and EGCG added during the lipid mixing stage. Data represents mean $\pm \mathrm{SD}$. $\mathrm{n}=3$ independent batches. $* * * *$ indicates statistical comparison between the size of liposome formulations with a $\mathrm{P} \leq 0.0001$. \# \# indicates statistical comparison between the polydispersity of liposome formulations with a $\mathrm{P} \leq 0.01$.

Fig. 2 Entrapment efficiency of EGCG in liposomes formulated with $0-10 \% \mathrm{w} / \mathrm{w}$ Tween 20

Entrapment efficiency (\%) of EGCG in liposomes formulated with varying amounts of Tween $20(0-10 \% \mathrm{w} / \mathrm{w})$ Data represents mean \pm SD. $\mathrm{n}=3$ independent batches. $* * * *$ indicates statistical comparison between the entrapment efficiency of liposome formulations with a $\mathrm{P} \leq$ 0.0001 .

\section{Fig. 3 Deformability index for 'empty' and EGCG loaded liposomes}

Deformability index following extrusion through $50 \mathrm{~nm}$ membranes for 'empty' and EGCG loaded liposomes with increasing surfactant loading up to a maximum of $10 \% \mathrm{w} / \mathrm{w}$. Liposomes were prepared adapting the dry film method adding the surfactant and adding EGCG during the lipid mixing stage. The preparation was vortexed and then extruded though the membranes. Data represents mean \pm SD. $\mathrm{n}=3$ independent batches. $* * * *$ indicates statistical comparison between the DI of liposome formulations with a $\mathrm{P} \leq 0.0001$.

Fig. 4 Differential scanning calorimetry scan of EGCG

All experimental runs commenced at an initial temperature of $0{ }^{\circ} \mathrm{C}$ with a scan rate of 10 ${ }^{\circ} \mathrm{C} / \mathrm{min}$ to $300{ }^{\circ} \mathrm{C}$. Peak a and b are related to the epimer of EGCG, GCG. Peak c represents the glass transition temperature $\left(\mathrm{T}_{\mathrm{c}}\right)$ of EGCG was at $220^{\circ} \mathrm{C}$ and the melting point $\left(\mathrm{T}_{\mathrm{m}}\right)$ of EGCG was at $245^{\circ} \mathrm{C}$.

Fig. 5 Differential scanning calorimetry analysis scans of PC, cholesterol and Tween 20 and EGCG blends

DSC analysis scans of (A) PC, cholesterol and Tween 20 blend and (B) PC, cholesterol, Tween 20 and EGCG blend. The $\mathrm{T}_{\mathrm{m}}$ of the lipid mixture is $172{ }^{\circ} \mathrm{C}$, and upon addition of EGCG, the $\mathrm{T}_{\mathrm{m}}$ was $191{ }^{\circ} \mathrm{C}$. All experimental runs started at an initial temperature of $0{ }^{\circ} \mathrm{C}$, purged under nitrogen gas, with a scan rate of $10{ }^{\circ} \mathrm{C} / \mathrm{min}$ to $300^{\circ} \mathrm{C}$.

Fig. 6 In-vitro percentage EGCG cumulative release profiles from solution and liposomal formulations

EGCG release profiles from solution and liposomes formulated with $0,2,6$ or $10 \% \mathrm{w} / \mathrm{w}$ Tween 20 over 24 hours. Liposomes were prepared adapting the dry film method adding the surfactant and EGCG during the lipid mixing stage. A diffusion cell dialysis system was used to evaluate in-vitro drug release. Data represents mean $\pm \mathrm{SD}$. $\mathrm{n}=3$ independent batches. $* * * *$ 
899 indicates statistical comparison between the EGCG release of liposome formulations with a P

$900 \leq 0.0001$

901 Fig. 7 Stability of EGCG loaded liposomes as determined by size

902 Size of EGCG loaded liposomes formulated with $0-10 \% \mathrm{w} / \mathrm{w}$ Tween 20, using DLS, 903 formulated with up to $10 \% \mathrm{w} / \mathrm{w}$ Tween 20 measured on various days $(1,7,14,21$ and 28).

904 Data represents mean \pm SD. $n=6$ independent batches.

905 Fig. 8 Liposome encapsulation efficiency for EGCG

906 Liposome encapsulation efficiency for EGCG in liposomes formulated with $2 \% \mathrm{w} / \mathrm{w}$ Tween 90720 liposomes over 28 days. Liposomes were prepared adapting the dry film method adding 908 the surfactant and drug during the lipid mixing stage. The preparation was then washed via 909 centrifugation. The quantity of EGCG in supernatant over 28 days was then analysed by 910 HPLC coupled with UV detection to assess liposome stability. Data represents mean $\pm \mathrm{SD}$. $911 \mathrm{n}=6$ independent batches.

\section{2}

Fig. 9 Cellular toxicity of EGCG

HDFa (A) and HaCat (B) cells were grown on a 96-well plate at a density of $50 \times 10^{3}$ cells per well and exposed to various concentrations of EGCG $(0.01-100 \mu \mathrm{M})$ for 24 hours. Thereafter $25 \mu \mathrm{L}$ of a 12.5:1 parts mixture of XTT to menadione was added each well. Plates were incubated for 3 hours at $37^{\circ} \mathrm{C}$ and the absorbance read at $450 \mathrm{~nm}$. Data is reported as mean \pm SD with 6 replicates per compound in at 3 independent experiments. $* * * *, * * *, * *, *$ indicates statistical comparison between the entrapment efficiency of liposome formulations with a $\mathrm{P} \leq 0.0001,0.001,0.01$ and 0.05 respectively.

Fig. 10 Localisation of DilC labelled liposomes loaded with EGCG and 2\% w/w Tween 20 in HaCat cells

Cells were grown on the coverslips for 2 days. Cell nuclei were visualised using (A) DAPI (Blue). Liposomes were formulated with DilC for visualisation (B) (yellow). Liposome localisation within the cell is shown in the merged image $(\mathrm{C})$.

Fig. 11 Localisation of DilC labelled liposomes loaded with EGCG and 2\% w/w Tween 20 in HDFa cells

Cells were grown on the coverslips for 2 days. Cell nuclei were visualised using (A) DAPI (Blue). Liposomes were formulated with DilC for visualisation (B) (yellow). Liposome localisation within the cell is shown in the merged image $(\mathrm{C})$. 